\title{
Aerosol lidar intercomparison in the framework of the EARLINET project. 3. Raman lidar algorithm for aerosol extinction, backscatter, and lidar ratio
}

\author{
Gelsomina Pappalardo, Aldo Amodeo, Marco Pandolfi, Ulla Wandinger, \\ Albert Ansmann, Jens Bösenberg, Volker Matthias, Vassilis Amiridis, \\ Ferdinando De Tomasi, Max Frioud, Marco larlori, Leonce Komguem, \\ Alexandros Papayannis, Francesc Rocadenbosch, and Xuan Wang
}

\begin{abstract}
An intercomparison of the algorithms used to retrieve aerosol extinction and backscatter starting from Raman lidar signals has been performed by 11 groups of lidar scientists involved in the European Aerosol Research Lidar Network (EARLINET). This intercomparison is part of an extended quality assurance program performed on aerosol lidars in the EARLINET. Lidar instruments and aerosol backscatter algorithms were tested separately. The Raman lidar algorithms were tested by use of synthetic lidar data, simulated at 355,532, 386, and $607 \mathrm{~nm}$, with realistic experimental and atmospheric conditions taken into account. The intercomparison demonstrates that the data-handling procedures used by all the lidar groups provide satisfactory results. Extinction profiles show mean deviations from the correct solution within $10 \%$ in the planetary boundary layer (PBL), and backscatter profiles, retrieved by use of algorithms based on the combined Raman elastic-backscatter lidar technique, show mean deviations from solutions within $20 \%$ up to $2 \mathrm{~km}$. The intercomparison was also carried out for the lidar ratio and produced profiles that show a mean deviation from the solution within $20 \%$ in the PBL. The mean value of this parameter was also calculated within a lofted aerosol layer at higher altitudes that is representative of typical layers related to special events such as Saharan dust outbreaks, forest fires, and volcanic eruptions. Here deviations were within 15\%. (C) 2004 Optical Society of America
\end{abstract}

OCIS codes: $\quad 010.3640,280.1100,290.1090,290.5860,290.2200$.

\section{Introduction}

Atmospheric aerosols, which originate both from natural sources and from human intervention, considerably affect the Earth's radiation balance, ${ }^{1,2}$ and they are considered to be one of the major

G. Pappalardo (pappalardo@imaa.cnr.it), A. Amodeo, and M. Pandolfi are with the Istituto di Metodologie per l'Analisi Ambientale, Consiglio Nazionale delle Richerche, Contrada S. Loja, 85050 Tito Scalo (Potenza), Italy. U. Wandinger and A. Ansmann are with Institute for Tropospheric Research, Permoserstrasse 15, 04303 Leipzig, Germany. When this research was conducted, J. Bösenberg and V. Matthias were with the Max-Planck-Institut für Meteorologie, Bundesstrasse 55, 20146 Hamburg, Germany; V. Matthias is now with Institute for Coastal Research, GKSS Research Center, Max-Planck-Strasse 1, 21502 Geesthacht, Germany. V. Amiridis is with the Laboratory of Atmospheric Physics, Aristotle University of Thessaloniki, Box 149, 54124 Thessaloniki, Greece. F. De Tomasi is with the Istituto Nazionale per la Fisica della Materia, Dipartimento di Fisica, Università di Lecce, via Arnesano, 73100 Lecce, Italy. M. Frioud is with the Observatory of Neuchâtel, Rue de l'Observatoire 58, 2000 sources of uncertainty in climate forcing predictions. For this reason, information on their global distribution, their vertical and horizontal extent, and their time of residence in the atmosphere are necessary.

Neuchâtel, Switzerland. M. Iarlori is with the Dipartimento di Fisica, Università degli Studi-L’Aquila, via Vetoio Loc. Coppito, 67010 L'Aquila, Italy. L. Komguem is with the Department of Physics, University of Wales, Aberystwyth Ceredigion SY23 3BZ, United Kingdom. A. Papayannis is with the Department of Physics, National Technical University of Athens, Heroon Polytechniou 9, 5780 Zografou, Greece. F. Rocadenbosch is with the Department of Signal Theory and Communication, Universitat Politècnica de Catalunya, Jordi Girona 1-3, Edif. D4-016, 08034 Barcelona, Spain. X. Wang is with the Istituto Nazionale per la Fisica della Materia, Complesso Universitario Monte S. Angelo, via Cintia, 80126 Napoli, Italy.

Received 30 November 2003; revised manuscript received 20 May 2004; accepted 27 May 2004.

0003-6935/04/285370-16\$15.00/0

C 2004 Optical Society of America 
Table 1. Locations of Participating Groups and Raman Algorithms Used

\begin{tabular}{lll}
\hline $\begin{array}{l}\text { Location of } \\
\text { Lidar Station }\end{array}$ & Code & \multicolumn{1}{c}{ Raman Algorithm } \\
\hline Aberystwyth & ab & Linear and quadratic fit \\
Athens & at & Sliding average filter and polynomial fit \\
Barcelona & ba & Weighted gliding window for spatial averaging, least-squares linear fit \\
Hamburg & hh & Sliding average \\
L'Aquila & la & Second-order digital Savitzky-Golay filter \\
Lecce & lc & Sliding linear least-squares fit \\
Leipzig & le & Sliding linear least-squares fit \\
Napoli & na & Sliding linear fit \\
Neuchâtel & ne & Sliding average \\
Potenza & po & Sliding linear least-squares fit \\
Thessaloniki & th & Least-squares fit \\
\hline
\end{tabular}

The European Aerosol Research Lidar Network (EARLINET) is the first European network of 22 advanced lidar stations operating to provide a quantitative climatological database of the horizontal, vertical, and temporal distribution of aerosols over Europe $^{3-6}$ Lidars are powerful tools for providing quantitative measurements of the optical properties of aerosols with high spatial and temporal resolution and with a high level of accuracy. In particular, the use of combined Raman elastic-backscatter lidar permits the independent measurement of aerosol extinction and backscatter as a function of height. ${ }^{7,8}$ It has long been known that the elastic-backscatter lidar system is limited by the fact that only one signal is measured, whereas two parameters, backscatter and extinction, determine the lidar signal. ${ }^{9}$ Three methods have been demonstrated to provide independent aerosol extinction measurements: highspectral-resolution lidar, ${ }^{10}$ Raman $\operatorname{lidar}^{7,8}$ and multiple zenith-angle measurements. ${ }^{11-13}$ The Raman and the high-spectral-resolution techniques both rely on the detection of a pure molecular backscatter signal, but the latter requires a much higher technical effort to suppress aerosol backscattering. For reasons of technical practicability, the preferred method within the EARLINET is a combination of Raman and elastic scattering at one emission wavelength near $355 \mathrm{~nm}$. A large effort on the part of the EARLINET community has been devoted to upgrading the Raman capability. At present, nine lidar stations are able to perform measurements of nitrogen Raman scattering in the UV simultaneously with elastic backscatter. One of these lidar stations (at Leipzig) is also able to measure nitrogen Raman scattering in the visible domain.

The Raman lidar technique has been widely and successfully used for measurements of aerosol extinction. The Raman lidar technique is also used for operational lidar systems with automated data analysis. ${ }^{14}$ The most critical part of this method arises from the need to calculate the derivative of the logarithm of the ratio between the atmospheric number density and the range-corrected lidar-received power in conjunction with data averaging and handling operations. Much care is needed in data-averaging and -handling operations to prevent miscalculation in the estimation of both the aerosol extinction coefficient and the statistical error.

Because of the importance of the Raman technique, data simulations to test and to improve Raman algorithms used by each group of scientists within the EARLINET network have been prepared.4,15 Furthermore, the simulations serve to draw attention to special problems, such as appropriate averaging and error determination, in the analysis of Raman lidar data.

In this paper we present the results of an intercomparison of the algorithms used for retrieving aerosol extinction and backscatter by use of a Raman lidar, performed by the 11 groups of scientists within EARLINET whose locations are listed in Table 1. All these groups, except for the Neuchâtel and Barcelona groups that participated in this intercomparison with the intention to upgrade their systems with a Raman channel in near future, have a lidar system with a Raman channel. Algorithms used for the Raman extinction retrieval were tested with synthetic lidar data, with realistic experimental conditions that are common for most of the groups and with realistic aerosol load and properties taken into account.

This paper is the third in a sequence of papers about aerosol lidar intercomparisons in the framework of the EARLINET. These intercomparison experiments were performed to produce a high-quality standard of data originating from different systems within the network. The results of the instrument intercomparison were published in part one of the series, ${ }^{5}$ and those related to the aerosol backscatter algorithm intercomparison, starting from elastic lidar signals, were published in part two. ${ }^{6}$

This paper completes the algorithm intercomparison experiment, with an intercomparison of the algorithms for the independent retrieval of both aerosol extinction and backscatter starting from Raman and elastic lidar signals. The paper is organized as follows: In Section 2 a brief description of the Raman method is presented. Section 3 is devoted to a discussion of the data analysis applied for retrieving the aerosol extinction coefficient, including data han- 
dling, sources of error, and calculation of the effective spatial resolution. In Section 4 the simulation used for the intercomparison is described. In Section 5 the results from the various participating teams of scientists are presented and discussed: Besides the deviations between the retrieved aerosol extinction profiles and the initial profile used in the simulation, the results of the intercomparison of the retrieved aerosol backscatter profiles obtained by use of the combined Raman elastic-backscatter lidar method and of the lidar ratio profiles obtained from the independent retrieval of the aerosol extinction and backscatter profiles are reported, as well.

\section{Methodology}

Raman scattering is an inelastic pure molecular scattering ${ }^{16}$ that has been successfully used in lidar remote-sensing techniques since the late $1960 \mathrm{~s} .{ }^{17-19}$ In a Raman lidar, wavelength $\lambda_{R}$ of the scattered light is shifted with respect to emitted laser wavelength $\lambda_{L}$, and such a shift depends on the scattering molecule. ${ }^{16}$ For detection of the Raman scattering of a gas with known atmospheric density, such as nitrogen or oxygen, the backscatter coefficient in the Raman lidar equation is known, and only the aerosol extinction and its wavelength dependence remain as unknowns. ${ }^{7}$

The Raman lidar equation can be written as

$$
\begin{aligned}
P\left(\lambda_{R}, z\right)= & P\left(\lambda_{L}\right) C_{R}(z) \frac{\beta_{R}\left(\lambda_{L}, z\right)}{z^{2}} \exp \left\{-\int_{0}^{z}\left[\alpha\left(\lambda_{L}, \zeta\right)\right.\right. \\
& \left.\left.+\alpha\left(\lambda_{R}, \zeta\right)\right] \mathrm{d} \zeta\right\},
\end{aligned}
$$

where $P\left(\lambda_{R}, z\right)$ is the power received from distance $z$ at Raman wavelength $\lambda_{R}, P\left(\lambda_{L}\right)$ is the emitted power at wavelength $\lambda_{L}, C_{R}(z)$ is a function that depends on the overlap function and on all the rangeindependent system parameters, $\beta_{R}(\lambda, z)=N(z) \sigma_{R}(\lambda)$ is the Raman backscatter coefficient, where $N(z)$ is the atmospheric number density of the Raman scatterer and $\sigma_{R}(\lambda)$ is the Raman backscatter cross section, $\alpha$ is the range-dependent total volumetric extinction coefficient at wavelengths $\lambda_{L}$ and $\lambda_{R}$, and $\zeta$ is the range integration variable.

Assuming a wavelength dependence of the aerosol extinction $\alpha_{\text {aer }} \propto \lambda^{-k}$, the Raman lidar equation can be solved for the aerosol extinction at the emitted laser wavelength ${ }^{7}$ as

$$
\begin{aligned}
& \alpha_{\text {aer }}\left(\lambda_{L}, z\right)= \\
& \quad \frac{\frac{\mathrm{d}}{\mathrm{d} z} \ln \left[\frac{N(z)}{P\left(\lambda_{R}, z\right) z^{2}}\right]-\alpha_{\mathrm{mol}}\left(\lambda_{L}, z\right)-\alpha_{\mathrm{mol}}\left(\lambda_{R}, z\right)}{1+\left(\lambda_{L} / \lambda_{R}\right)^{k}},
\end{aligned}
$$

where $\mathrm{d} \sigma_{R}(\lambda) / \mathrm{d} z=0$ has been used. The molecular extinction can be calculated from Rayleigh scattering coefficients and atmospheric number density profiles retrieved from models or radiosonde measurements.
With the detection of the Raman scattered light, independent aerosol extinction profiles can be determined. One can also use this information to derive the aerosol backscatter without any assumption about the extinction-to-backscatter ratio (lidar ratio), ${ }^{20}$ which is an important parameter because it is directly related to the microphysical properties of the particles. One then calculates the backscatter profile by forming the ratio of the elastic and the Raman backscattered signals at height $z$ and at a calibration height $z_{0}$, with an assumption about the reference value of the aerosol backscatter at height $z_{0}$, $\beta_{\text {aer }}\left(z_{0}\right) .{ }^{21-23}$

\section{Data Analysis}

In the analysis of Raman lidar measurements of aerosol extinction [Eq. (2)] it is necessary to calculate the derivative of the logarithm of the ratio between the atmospheric number density and the range-corrected lidar-received power. The statistical fluctuations of the Raman lidar signal can produce large fluctuations in the derivative and thus in the aerosol extinction profile. Therefore the employment of datasmoothing techniques is generally necessary.

Several methods such as data binning, sliding averages, Kaiser filters, ${ }^{24}$ and Savitsky-Golay filters ${ }^{25}$ are usually employed for handling lidar signals. A further method is the calculation of the derivative by means of the least-squares technique, after the logarithmic function in Eq. (2) has been approximated with a first- or -second order polynomial within a height range. ${ }^{26}$ It is important to note, however, that the application of a particular method of data handling influences not only the final result but also the spatial resolution and the error.

\section{A. Errors}

For calculation of the aerosol extinction coefficient it is important to consider the main sources of uncertainties, which are as follows:

(a) The statistical error that is due to signal detection, ${ }^{26}$

(b) The systematic error associated with the estimate of temperature and pressure profiles, $8,27,28$

(c) The systematic error associated with the estimate of the ozone profiles in the UV, ${ }^{8}$

(d) The systematic error associated with wavelength-dependence parameter $k, 8,26,29,30,31$

(e) The systematic error associated with multiple scattering, $8,26,32$

(f) The error introduced by data-handling procedures such as signal averaging during varying atmospheric extinction and scattering conditions. ${ }^{8,33}$

In this paper we present an intercomparison of several algorithms for the retrieval of aerosol extinction starting from synthetic data, and for this reason only statistical errors that are due to signal detection are taken into account; all the systematic effects are neglected. For this intercomparison, each lidar group provided profiles with their corresponding er- 


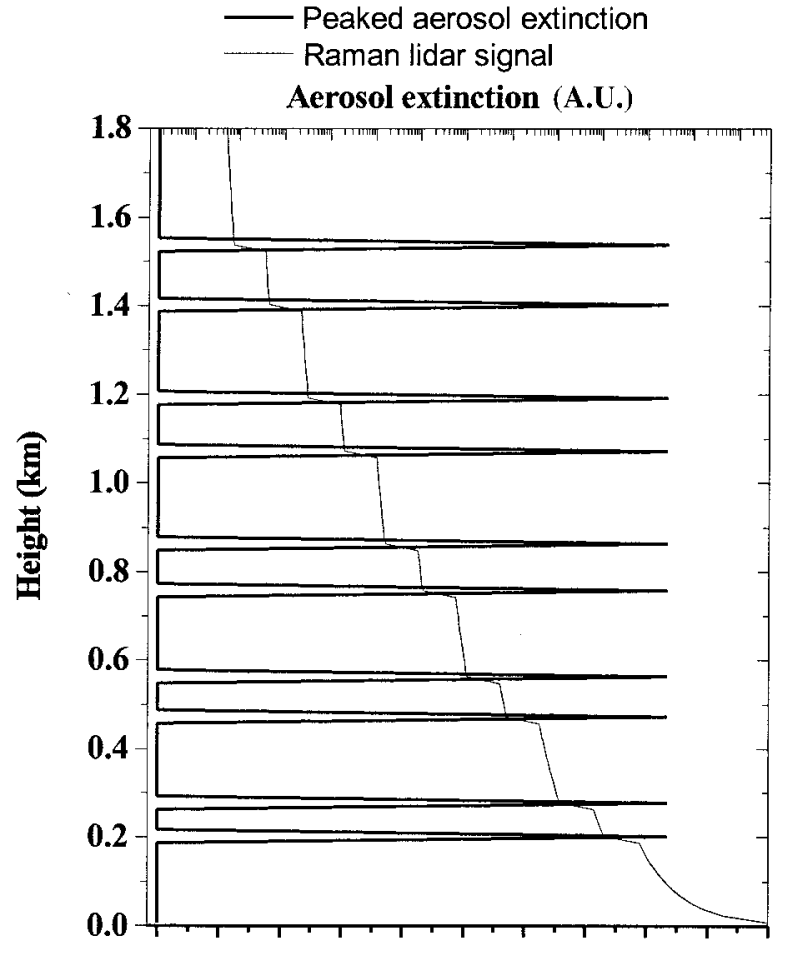

Raman lidar signal @ 355 nm (A.U.)

(a)
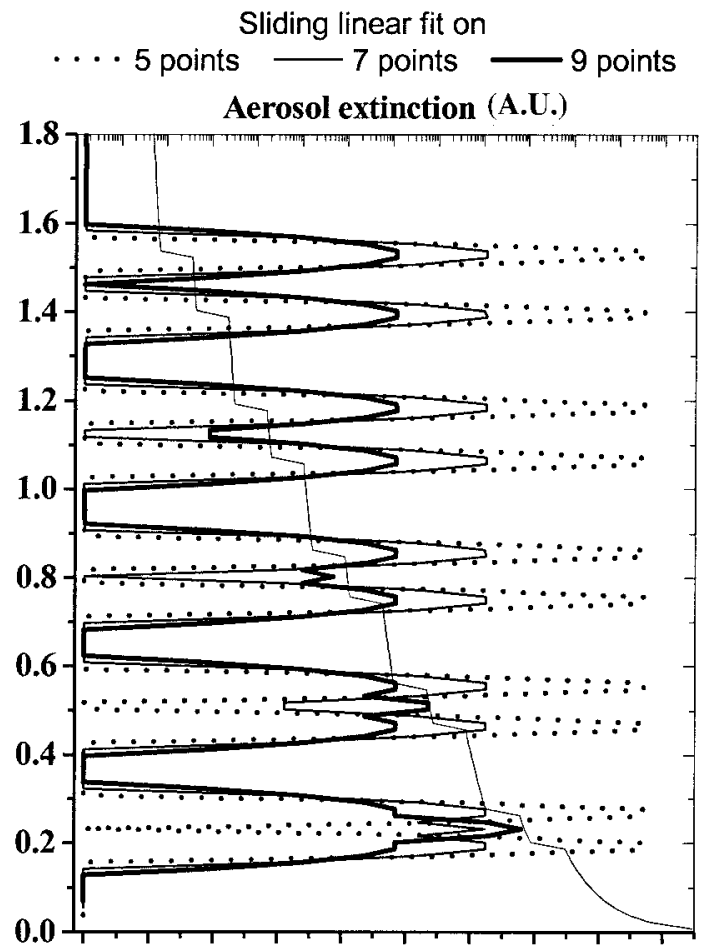

Raman lidar signal @355 nm (A.U.)

(b)

Fig. 1. (a) Synthetic Raman lidar signal at $355 \mathrm{~nm}$ (on a log scale) with a step structure and the corresponding peaked aerosol extinction profile (on a linear scale) that are zero everywhere except for a series of couples of heights separated by 75, 90, 105, 120, and 135 m, starting from the low heights. (b) Aerosol extinction profiles retrieved by application of the 5-, 7-, and 9-point sliding linear fits to the synthetic Raman lidar stepping signal.

rors, which were calculated by analytical or numerical techniques. Analytical calculation is performed by application of the error propagation rules in Eq. (2). When complicated or nonlinear data-handling procedures are applied, a numerical procedure based on a Monte Carlo technique could be useful. This procedure is based on the random extraction of new lidar signals, each bin of which is considered a sample element of a given probability distribution with the experimentally observed mean value and standard deviation. The extracted lidar signals are then processed with the same algorithm to produce a set of solutions from which the standard deviation is calculated as a function of height. Using both analytical and numerical procedures will produce an error that will depend on the noise of the signal and on the particular algorithm used.

\section{B. Effective Spatial Resolution}

As was mentioned at the beginning of this section, the application of a particular procedure of data-handling influences the effective spatial resolution. In fact, even if the retrieved extinction profile presents the same spatial resolution as do the raw Raman lidar data, the data-handling procedures that are included in the algorithm used to retrieve aerosol extinction produce a loss of information that results in lower spatial resolution, which we call the effective spatial resolution. To test the effective spatial resolution for the algorithm used, we use a step function method. This method checks the ability to resolve two narrow and well-separated structures in the aerosol extinction profile. In this method an ideal synthetic Raman lidar signal is generated; an aerosol extinction profile that equals zero everywhere except at two heights is used as input data. The synthetic Raman lidar signal shows a step structure, with two jumps that coincide with the two heights where the aerosol extinction is different from zero. By selecting the type of data handling and changing the distance between the two peaked structures in the aerosol extinction profile it is possible to check the minimum distance for which the two retrieved peaks are resolved according to the Rayleigh criterion ${ }^{34}$ that is commonly used in spectroscopy to decide when two neighboring spectral lines can be considered resolved. This minimum distance is the effective spatial resolution of the retrieved aerosol extinction profile.

Figure 1 shows the application of the step function method. Figure 1(a) shows an aerosol extinction profile that is equal to zero everywhere except at a number of heights where peaks are present. The aerosol extinction profile in the figure has a spatial resolution of $15 \mathrm{~m}$ and consists of 5 pairs of peaks that are separated by $5,6,7,8$, and 9 points, which correspond to $75,90,105,120$, and $135 \mathrm{~m}$, respectively. 
The same figure also shows the corresponding nitrogen Raman lidar signal simulated at $355 \mathrm{~nm}$ and characterized by steps that coincide with the peaks of the aerosol extinction profile. In Fig. 1(b) the results of the application of the sliding linear fit algorithm to the synthetic Raman lidar signal are illustrated: 5-, 7-, and 9-point sliding linear fits have been applied. For example, the 9-point sliding linear fit is able to resolve perfectly the two peaks separated by $135 \mathrm{~m}$ (from 1.4 to $1.6 \mathrm{~km}$ of height), and it is also able to resolve the two peaks separated by $120 \mathrm{~m}$ (1 to $1.2 \mathrm{~km}$ of height) according to the Rayleigh criterion, but it is not able to resolve the two peaks separated by $105 \mathrm{~m}$ ( 0.7 to $0.9 \mathrm{~km}$ of height); therefore the effective resolution of the 9-point sliding linear fit is $120 \mathrm{~m}$. In the same way, Fig. 1(b) shows that the 7-point sliding linear fit is able to resolve all the peaks up to the minimum separation of $90 \mathrm{~m}$ (from 0.4 to $0.6 \mathrm{~km}$ of height); therefore, in this case, the effective spatial resolution is $90 \mathrm{~m}$. The 5-point sliding linear fit is able to resolve all the peaks of the aerosol extinction because the minimum separation of the peaks in this example is just $75 \mathrm{~m}$, corresponding to 5 points.

It is important to note that the effective spatial resolution is always better than the expected resolution, based just on the number of points used in the data-smoothing procedure: In fact, in the 9-point sliding linear fit the effective resolution is 120 instead of $135 \mathrm{~m}$, and for the 7-point sliding linear fit the effective resolution is 90 instead of $105 \mathrm{~m}$. This technique was used by all the lidar groups to retrieve the effective spatial resolution of the solutions in the intercomparison.

\section{Intercomparison of the Raman Lidar Algorithms}

The main goal of the Raman algorithm intercomparison experiment is to test the algorithms used by each group within the EARLINET network for the retrieval of the aerosol extinction profile starting from nitrogen Raman lidar signals. This intercomparison experiment has the further purpose of testing the algorithm used for the independent retrieval of the aerosol backscatter and of the lidar ratio. For this purpose, synthetic Raman and elastic lidar signals were generated, with typical experimental conditions and realistic aerosol properties and load taken into account. The intercomparison was blind, to reproduce real conditions in which the solution is not known but also to prevent any possible influence on the groups in their retrieval of the results.

Synthetic elastic and Raman lidar signals at 355 and $532 \mathrm{~nm}$ were calculated with a lidar simulation model designed by the Institute for Tropospheric Research, Leipzig, Germany. Temperature, pressure, extinction, backscatter, and lidar ratio profiles, as shown in Fig. 2, were used as input data. In the
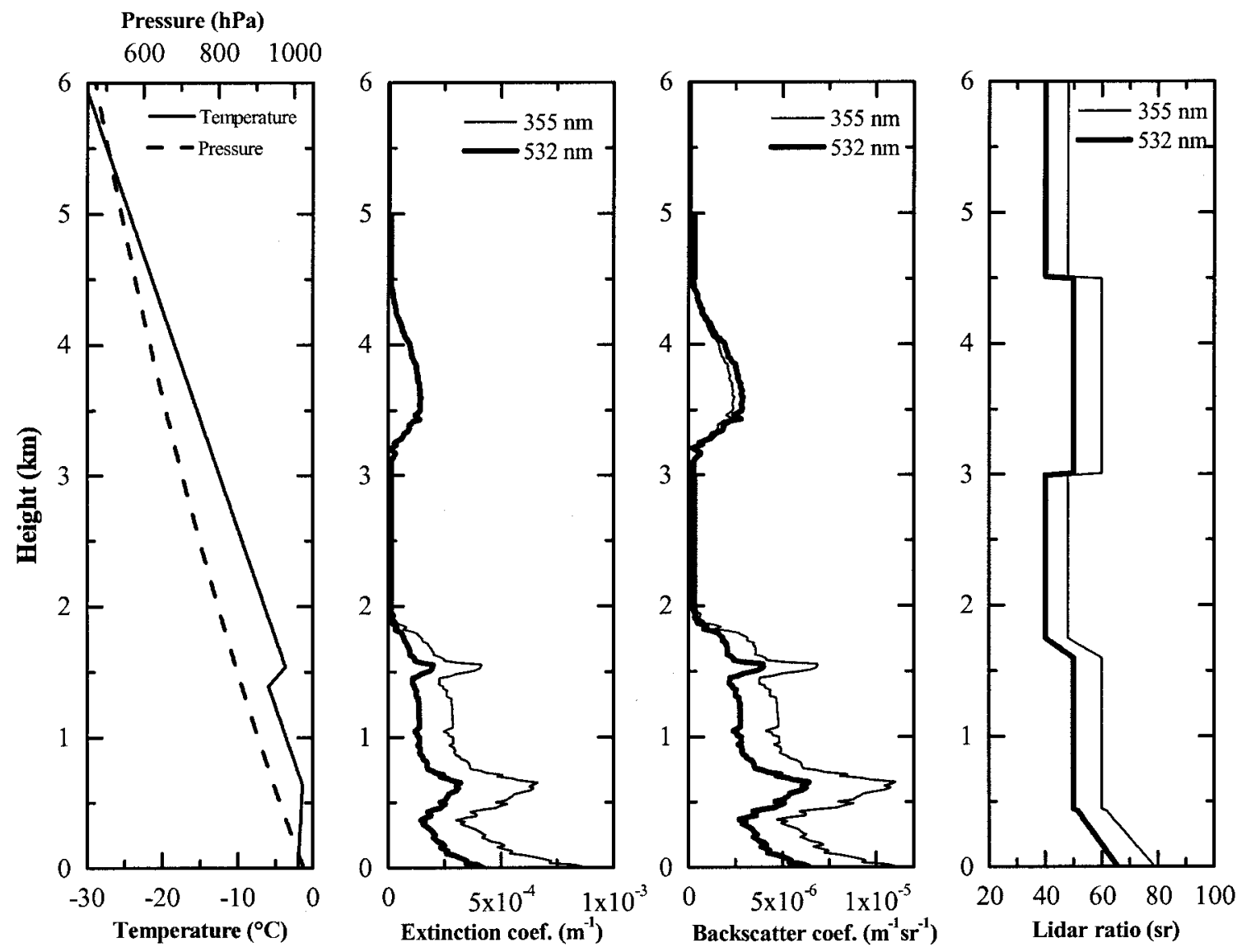

Fig. 2. Input data for the simulation at $355 \mathrm{~nm}$ (thinner curves) and at $532 \mathrm{~nm}$ (thicker curves). 


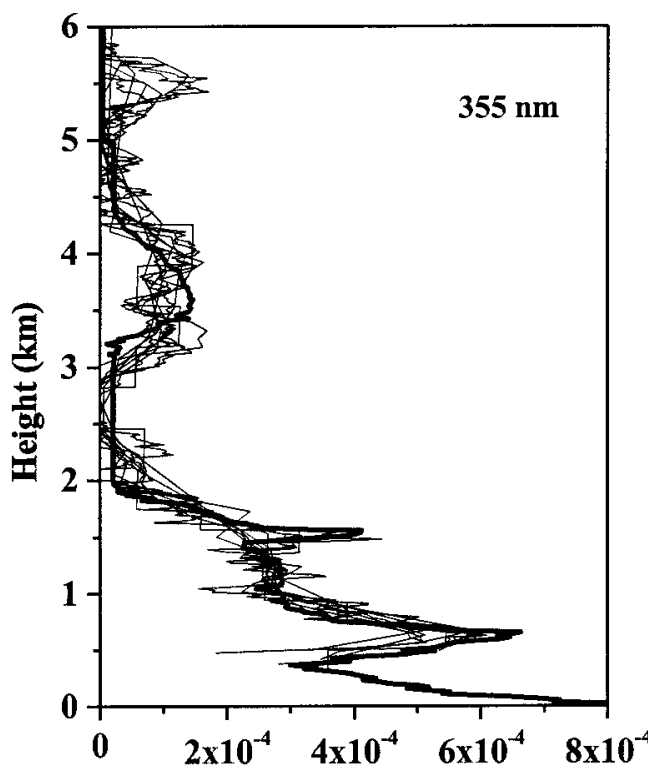

Extinction coefficient $\left(\mathbf{m}^{-1}\right)$

(a)

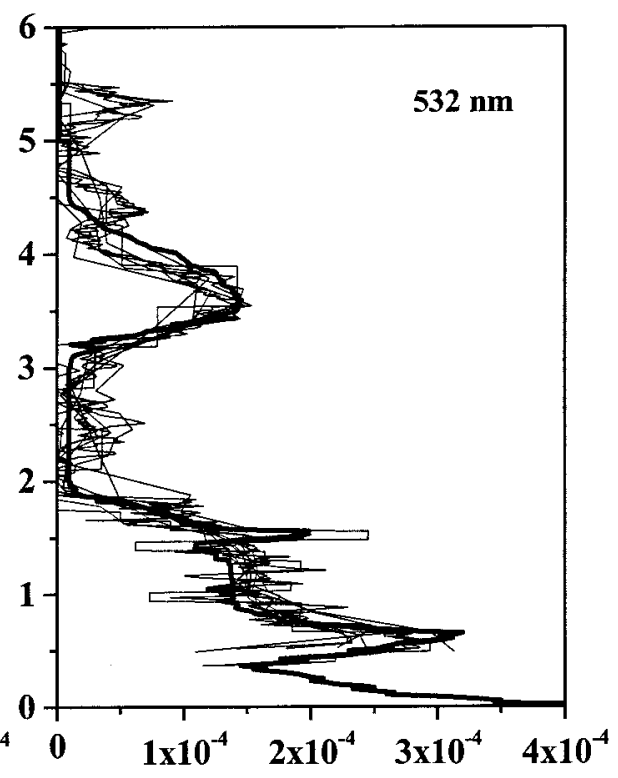

Extinction coefficient $\left(\mathrm{m}^{-1}\right)$

(b)

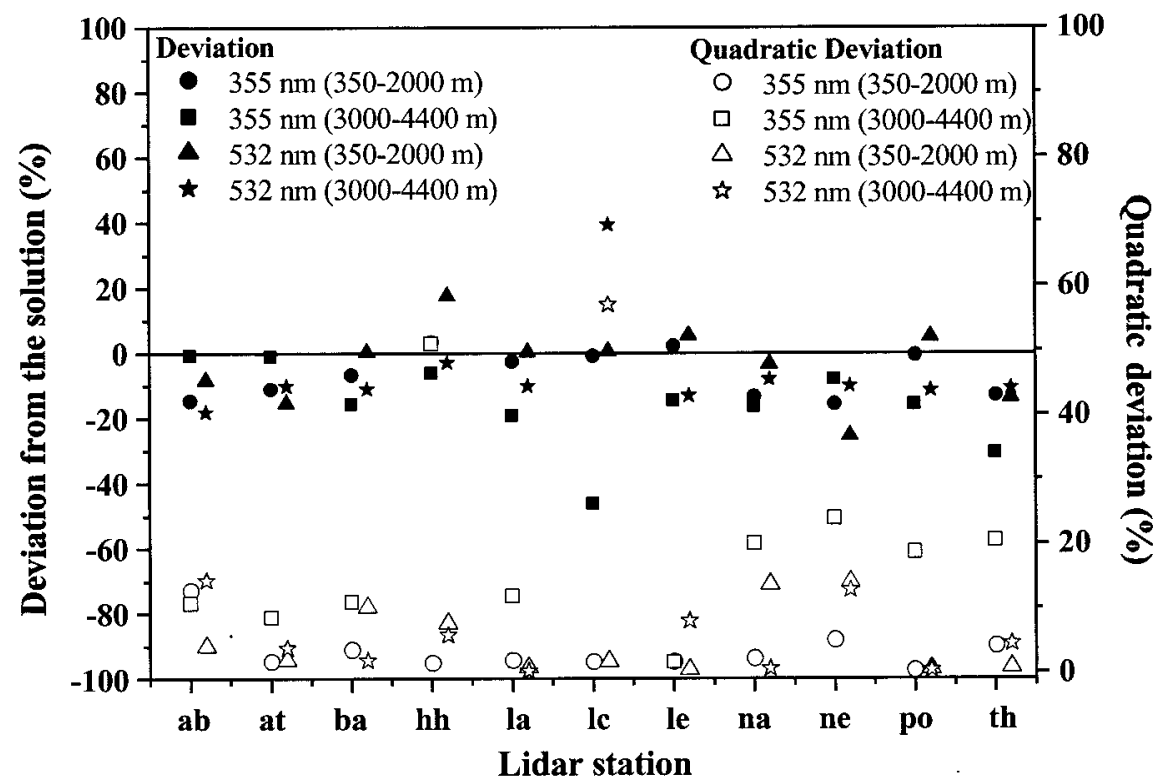

(c)

Fig. 3. (a), (b) Comparison of the extinction coefficient profiles retrieved at $355 \mathrm{~nm}$ and at $532 \mathrm{~nm}$ by each lidar station, and the corresponding solutions (thicker curves). (c) Mean deviations and mean quadratic deviations between the solution and the retrieved aerosol extinction profiles at 355 and $532 \mathrm{~nm}$, calculated for two different height ranges (Stage I).

temperature profile an inversion is present at $\sim 1.5$ $\mathrm{km}$ of altitude, with a corresponding peak in the extinction and backscatter profiles. In the lower height range, aerosol is present up to $\sim 2 \mathrm{~km}$ of altitude, which is representative of a typical aerosol load in a well-developed planetary boundary layer. ${ }^{5}$ From 3.5 to $4 \mathrm{~km}$, a lofted layer is simulated. The wavelength-dependence parameter, $k$, was set to 1.8 for the entire profile. Synthetic elastic and Raman lidar signals were simulated for a $20-\mathrm{Hz}$ laser system and an acquisition system with a maximum photon counting rate of $20 \mathrm{MHz}$, which would result in a maximum number of 4800 counts per range bin in a 2 -min profile with a spatial resolution of $15 \mathrm{~m}$. The fixed maximum counting rate of $20 \mathrm{MHz}$ leads to synthetic Raman lidar signals with a typical signal- 


\begin{tabular}{|c|c|c|}
\hline \multirow{2}{*}{$\begin{array}{l}\text { Lidar } \\
\text { Station }\end{array}$} & \multicolumn{2}{|c|}{ Spatial Resolution } \\
\hline & At $355 \mathrm{~nm}$ & At $532 \mathrm{~nm}$ \\
\hline $\mathrm{ab}$ & $\begin{array}{l}75 \mathrm{~m} \text { up to } 1500 \mathrm{~m}, 225 \mathrm{~m} \text { up to } 4.5 \mathrm{~km} \text {, } \\
\text { and } 375 \mathrm{~m} \text { above } 4.5 \mathrm{~km}\end{array}$ & $\begin{array}{l}150 \mathrm{~m} \text { up to } 1725 \mathrm{~m} \text { and } 300 \mathrm{~m} \\
\text { above } 1725 \mathrm{~m}\end{array}$ \\
\hline at & $\begin{array}{l}45 \mathrm{~m} \text { up to } 800 \mathrm{~m}, 75 \mathrm{~m} \text { up to } 4000 \mathrm{~m} \text {, } \\
\text { and } 105 \mathrm{~m} \text { above } 4000 \mathrm{~km}\end{array}$ & $\begin{array}{l}45 \mathrm{~m} \text { up to } 1000 \mathrm{~m}, 75 \mathrm{~m} \text { up to } \\
4000 \mathrm{~m} \text {, and } 105 \mathrm{~m} \text { above } 4000 \\
\mathrm{~m}\end{array}$ \\
\hline ba & $\begin{array}{l}210 \mathrm{~m} \text { up to } 1747.5 \mathrm{~m}, 360 \mathrm{~m} \text { up to } \\
4627.5 \mathrm{~m} \text {, and } 1440 \mathrm{~m} \text { up to } 6007.5 \mathrm{~m}\end{array}$ & $\begin{array}{l}90 \mathrm{~m} \text { up to } 1747.5 \mathrm{~m}, 360 \mathrm{~m} \text { up } \\
\text { to } 4627.5 \mathrm{~m} \text {, and } 720 \mathrm{~m} \text { up to } \\
6007.5 \mathrm{~m}\end{array}$ \\
\hline $\mathrm{hh}$ & $\begin{array}{l}180 \mathrm{~m} \text { up to } 1387 \mathrm{~m} \text { and } 480 \mathrm{~m} \text { above } \\
1387 \mathrm{~m}\end{array}$ & $\begin{array}{l}180 \mathrm{~m} \text { up to } 1387 \mathrm{~m} \text { and } 480 \mathrm{~m} \\
\text { above } 1387 \mathrm{~m}\end{array}$ \\
\hline la & $100-700 \mathrm{~m}$, linearly increasing & $100-700 \mathrm{~m}$, linearly increasing \\
\hline lc & $\begin{array}{l}150 \mathrm{~m} \text { up to } 1750 \mathrm{~m} \text { and } 450 \mathrm{~m} \text { above } \\
1750 \mathrm{~m}\end{array}$ & $\begin{array}{l}150 \mathrm{~m} \text { up to } 1500 \mathrm{~m} \text { and } 450 \mathrm{~m} \\
\text { above } 1500 \mathrm{~m}\end{array}$ \\
\hline le & $\begin{array}{l}160 \mathrm{~m} \text { up to } 750 \mathrm{~m}, 320 \mathrm{~m} \text { up to } 2100 \\
\mathrm{~m} \text {, and } 1060 \mathrm{~m} \text { above } 2100 \mathrm{~m}\end{array}$ & $\begin{array}{l}160 \mathrm{~m} \text { up to } 700 \mathrm{~m}, 320 \mathrm{~m} \text { up } \\
\text { to } 2000 \mathrm{~m} \text {, and } 800 \mathrm{~m} \text { above } \\
2000 \mathrm{~m}\end{array}$ \\
\hline na & $180 \mathrm{~m}$ fixed & $180 \mathrm{~m}$ fixed \\
\hline ne & 150-825 m, linearly increasing & 150-825 m, linearly increasing \\
\hline po & $\begin{array}{l}150 \mathrm{~m} \text { up to } 900 \mathrm{~m}, 300 \mathrm{~m} \text { up to } 2000 \\
\mathrm{~m} \text {, and } 780 \mathrm{~m} \text { above } 2000 \mathrm{~m}\end{array}$ & $\begin{array}{l}150 \text { up to } 700 \mathrm{~m}, 300 \text { up to } \\
1900 \mathrm{~m} \text {, and } 735 \text { above } 1900 \mathrm{~m}\end{array}$ \\
\hline th & $\begin{array}{l}45 \mathrm{~m} \text { up to } 800 \mathrm{~m} \text { and } 75 \mathrm{~m} \text { above } 800 \\
\mathrm{~m}\end{array}$ & $\begin{array}{l}45 \mathrm{~m} \text { up to } 800 \mathrm{~m} \text { and } 75 \mathrm{~m} \\
\text { above } 800 \mathrm{~m}\end{array}$ \\
\hline
\end{tabular}

to-noise ratio of $\sim 5$ at $2 \mathrm{~km}$ of altitude and of less than 2 at altitudes above $4 \mathrm{~km}$. For this intercomparison, a series of 15 profiles with 2400 laser shots each (corresponding to a temporal average of $30 \mathrm{~min}$ ) and with a spatial resolution of $15 \mathrm{~m}$ was generated for each wavelength. All these conditions produce an overall lidar signal with a typical signal-to-noise ratio (SNR) of $\sim 20$ at $2 \mathrm{~km}$ of altitude and of less than 10 at altitudes above $4 \mathrm{~km}$. In this case, typical statistical errors, which are due to the signal, are $\sim 5 \%$ and $\sim 4 \%$ at $2 \mathrm{~km}$ of altitude at 355 and $532 \mathrm{~nm}$, respectively, and $\sim 15 \%$ and $\sim 9 \%$ at altitudes above 4 $\mathrm{km}$ at 355 and $532 \mathrm{~nm}$, respectively. These statistical errors produce errors in the retrieved aerosol extinction profiles that are typically $\sim 25 \%$ at $2 \mathrm{~km}$ of altitude and $\sim 40 \%$ at $4 \mathrm{~km}$ of altitude, depending on the Raman algorithm used and on the spatial reso- lution. For the aerosol backscatter these errors are typically $\sim 20 \%$ at $2 \mathrm{~km}$ of altitude and $\sim 30 \%$ at $4 \mathrm{~km}$ of altitude. In the simulation, an incomplete overlap of laser beam and receiver field of view below $300 \mathrm{~m}$ was introduced.

The intercomparison was performed in two stages. For the first stage (Stage I), only the synthetic Raman and elastic lidar signals were distributed, without any further information except for the ground values of temperature and pressure $\left(T=-2{ }^{\circ} \mathrm{C}, P=1025\right.$ $\mathrm{hPa}$. In Stage I, each lidar group was asked to provide extinction and backscatter profiles up to $6-\mathrm{km}$ height and lidar ratio profiles up to $4-\mathrm{km}$ height for each wavelength ( 355 and $532 \mathrm{~nm}$ ). In this stage the main goal was to test the accuracy of the algorithms used by all the groups for the retrieval of aerosol extinction and backscatter in typical measurement

Table 3. Mean Absolute Deviations of the Aerosol Extinction $\left(\times 10^{-4} \mathrm{~m}^{-1}\right)$ for Three Altitude Ranges (Stage I)

\begin{tabular}{|c|c|c|c|c|c|c|}
\hline \multirow{2}{*}{$\begin{array}{c}\text { Lidar } \\
\text { Station }\end{array}$} & \multicolumn{3}{|c|}{ At $355 \mathrm{~nm}$} & \multicolumn{3}{|c|}{ At $532 \mathrm{~nm}$} \\
\hline & $350-2000 \mathrm{~m}$ & $2000-3000 \mathrm{~m}$ & $3000-4400 \mathrm{~m}$ & $350-2000 \mathrm{~m}$ & $2000-3000 \mathrm{~m}$ & $3000-4400 \mathrm{~m}$ \\
\hline$a b$ & -0.57 & 0.02 & 0.02 & -0.11 & -0.01 & -0.19 \\
\hline at & -0.18 & -0.201 & 0.05 & -0.25 & 0.09 & -0.03 \\
\hline ba & -0.21 & 0.26 & 0.07 & -0.001 & 0.05 & -0.03 \\
\hline hh & 0.32 & -0.07 & 0.15 & 0.38 & 0.12 & -0.01 \\
\hline la & -0.06 & -0.11 & 0.06 & 0.04 & 0.09 & -0.05 \\
\hline lc & 0.05 & 0.63 & 0.42 & 0.06 & -0.06 & 0.22 \\
\hline le & 0.12 & -0.01 & $-8 \times 10^{-5}$ & 0.12 & 0.04 & -0.07 \\
\hline na & -0.42 & -0.08 & 0.07 & 0.003 & 0.04 & -0.09 \\
\hline ne & -0.51 & 0.11 & 0.07 & -0.41 & 0.03 & -0.11 \\
\hline po & 0.03 & 0.08 & 0.08 & 0.10 & 0.03 & -0.06 \\
\hline th & -0.12 & -0.38 & -0.35 & -0.10 & 0.04 & 0.06 \\
\hline
\end{tabular}




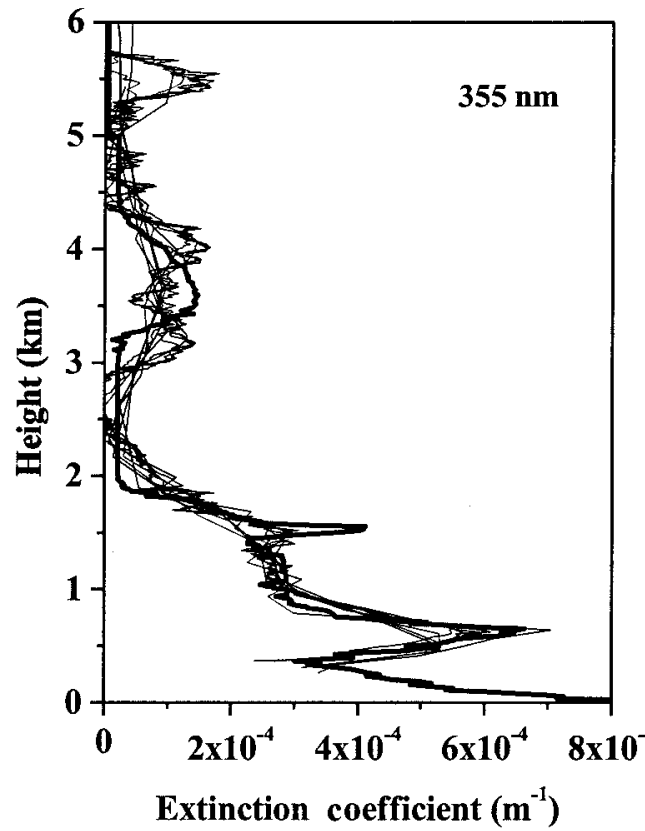

(a)

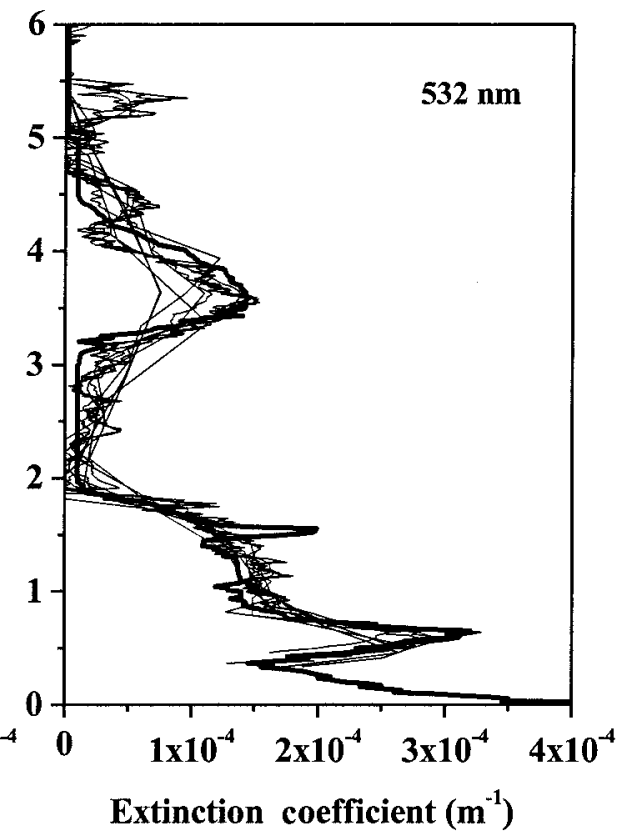

(b)

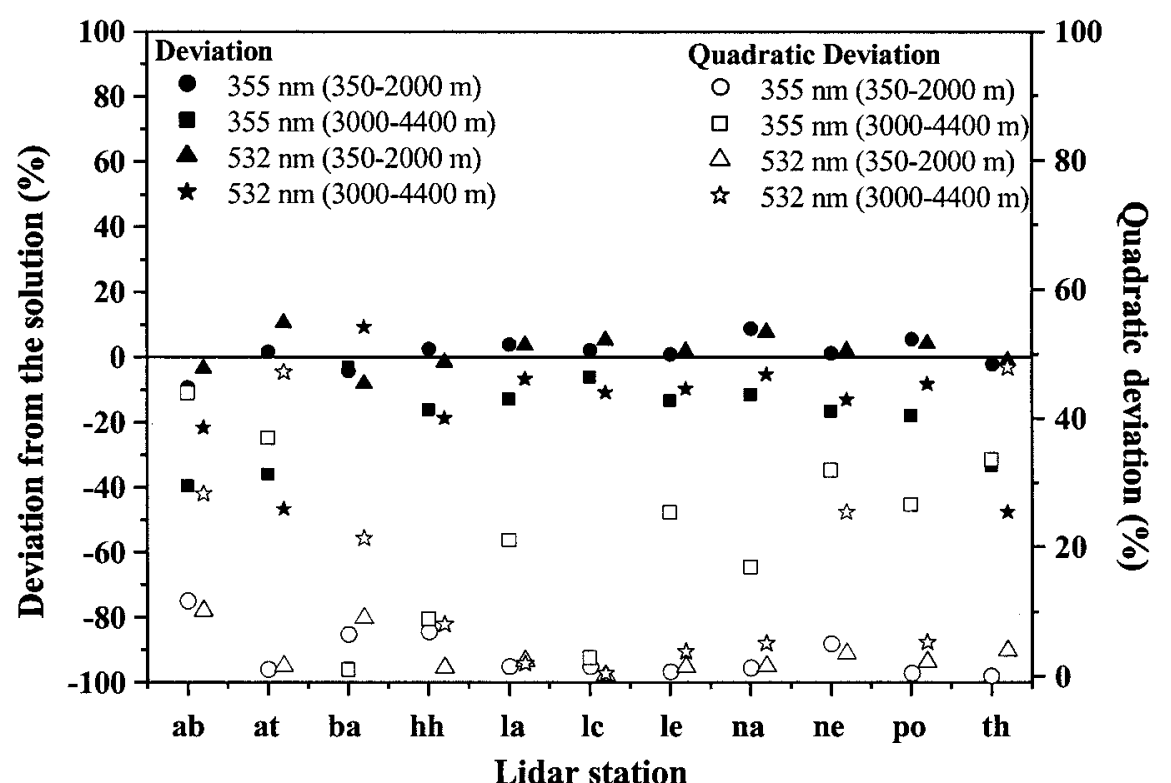

(c)

Fig. 4. (a), (b) Comparison of the extinction coefficient profiles retrieved at $355 \mathrm{~nm}$ and at $532 \mathrm{~nm}$ by each lidar station, and the corresponding solutions (thicker curves). (c) Mean deviations and mean quadratic deviations between the solution and the retrieved aerosol extinction profiles at 355 and $532 \mathrm{~nm}$, calculated for two different height ranges (Stage II).

conditions when just Raman and elastic lidar signals and ground values of temperature and pressure are known.

The second stage of the intercomparison (Stage II) has been devoted to studying the differences in the results obtained with the various algorithms used. For this purpose, more constraints in this stage have been imposed: All systematic effects have been excluded and the atmospheric model (temperature and pressure profiles), the wavelength dependence, and the effective spatial resolution were fixed. With these constraints, the differences in the results for aerosol extinction, backscatter, and lidar ratio as well as for error calculation have to be ascribed only to the differences in the algorithms. For Stage II the following information was distributed:

- Wavelength dependence parameter $k=1.8$,

- Input pressure and temperature profiles, as given in Fig. 2, and

- Reference value for the backscatter at both 355 and $532 \mathrm{~nm}\left(8.63 \times 10^{-9}\right.$ and $5 \times 10^{-9} \mathrm{~m}^{-1} \mathrm{sr}^{-1}$ in 
Table 4. Mean Absolute Deviations of the Aerosol Extinction $\left(\times 10^{-4} \mathrm{~m}^{-1}\right)$ for Three Altitude Ranges (Stage II)

\begin{tabular}{|c|c|c|c|c|c|c|}
\hline \multirow{2}{*}{$\begin{array}{l}\text { Lidar } \\
\text { Station }\end{array}$} & \multicolumn{3}{|c|}{ At $355 \mathrm{~nm}$} & \multicolumn{3}{|c|}{ At $532 \mathrm{~nm}$} \\
\hline & $350-2000 \mathrm{~m}$ & $2000-3000 \mathrm{~m}$ & $3000-4400 \mathrm{~m}$ & $350-2000 \mathrm{~m}$ & $2000-3000 \mathrm{~m}$ & $3000-4400 \mathrm{~m}$ \\
\hline$a b$ & -0.28 & 0.12 & -0.09 & -0.02 & 0.17 & -0.18 \\
\hline at & 0.06 & -0.05 & -0.39 & 0.18 & 0.05 & -0.60 \\
\hline ba & -0.14 & 0.03 & -0.03 & -0.10 & 0.16 & 0.05 \\
\hline hh & 0.18 & 0.20 & -0.01 & 0.04 & 0.12 & -0.08 \\
\hline la & 0.19 & 0.11 & 0.12 & 0.07 & 0.06 & -0.01 \\
\hline lc & 0.13 & 0.17 & 0.09 & 0.12 & 0.05 & -0.05 \\
\hline le & 0.08 & 0.17 & 0.10 & 0.06 & 0.04 & -0.05 \\
\hline na & 0.33 & 0.19 & 0.13 & 0.16 & 0.10 & 0.01 \\
\hline ne & 0.09 & 0.02 & 0.05 & 0.07 & -0.01 & 0.03 \\
\hline po & 0.23 & 0.03 & 0.07 & 0.09 & 0.03 & -0.05 \\
\hline th & -0.09 & 0.16 & -0.45 & -0.05 & 0.09 & -0.57 \\
\hline
\end{tabular}

the $6-7-\mathrm{km}$ altitude range at 355 and $532 \mathrm{~nm}$, respectively);

and each group was asked to provide

(a) Extinction and backscatter profiles up to $6 \mathrm{~km}$ of height with a fixed resolution (150 m up to $700-\mathrm{m}$ height, $300 \mathrm{~m}$ up to $1900-\mathrm{m}$ height, and $735 \mathrm{~m}$ above 1900-m height) for both wavelengths and

(b) Lidar ratio profiles up to $2 \mathrm{~km}$ of height and mean lidar ratio values in the height range $3500-$ $4000 \mathrm{~m}$.

Each group used the step function method introduced in Section 3 to verify the effective spatial resolution produced by its own analysis algorithm.

To perform a quantitative evaluation of the quality of the various algorithms presented in Section 5, we considered two statistical estimators (parameters): weighted mean deviation and weighted mean quadratic deviation between the retrieved profiles and the solution, defined as

$$
\begin{gathered}
\text { mean deviation }=\left\langle\frac{x_{i}-s_{i}}{s_{i}}\right\rangle_{w}, \\
\text { mean quadratic deviation }=\left[\left\langle\left(\frac{x_{i}-s_{i}}{s_{i}}\right)^{2}\right\rangle_{w}\right]^{1 / 2},
\end{gathered}
$$

where $x_{i}$ and $s_{i}$ are the values of the retrieved solution and of the solution profile (simulated signal input profiles), respectively, at height $z_{i}$ and $w$ means weighted, where for weight we considered the statistical error related to $x_{i}$.

The mean deviation gives an evaluation of the mean difference between the results and the solution in a fixed height range, whereas the mean quadratic deviation gives an evaluation of the mean fluctuation of the results around the solution in a fixed height range.

This intercomparison can be regarded as successful if the deviations between the retrieved profiles and the solutions are below the maximum allowed deviations as fixed within the EARLINET for the instrument intercomparison experiment., 4 These limits can be adopted here also, because the noise level added to the synthetic lidar signals used for this intercomparison has been fixed such that the mean deviations from the solutions are expected to be within these limits.

\section{Intercomparison Results}

\section{A. Aerosol Extinction}

In Table 1, all the groups of scientists who participated in this intercomparison are listed by location, along with the Raman algorithm used. Figure 3 shows the extinction profiles provided by the various groups at both 355 and $532 \mathrm{~nm}$ for Stage I, compared with the solution, which is shown as a darker curve. As we said in Section 4, these results were obtained without any further information. Each group assumed pressure and temperature profiles and a specific value for parameter $k$. All groups provided extinction profiles with different spatial resolutions, which are listed in Table 2. In the first height range, up to $2000 \mathrm{~m}$, differences among the extinction profiles are within $20 \%$, and no significant bias was observed for either wavelength. In the height range $3000-4400 \mathrm{~m}$, where an aerosol layer is present in the solution, differences among the extinction profiles are typically within $20 \%$ again. In Fig. 3(c) the relative mean and the quadratic deviations between the extinction coefficients and the solution are given for both wavelengths in the 350-2000-m height range, which is representative of the planetary boundary layer, and in the 3000-4400-m height range where an aerosol layer is present. Mean deviations are within $15 \%$ in the $350-2000-m$ height range and within $20 \%$ in the 3000-4400-m height range at both wavelengths for most of the lidar stations. These results are consistent with the statistical errors, which, although there is a large variability for each group, are on average within $25 \%$ for the first height range and reach as much as 50\% in the second height range at both 355 and $532 \mathrm{~nm}$. Large errors in the second height range are strictly related to the low SNR level of $\sim 10$, with respect to the mean SNR of $\sim 70$ in the $350-2000-\mathrm{m}$ height region, whereas the differences in the errors for each group have to be ascribed to the use of different spatial resolutions. 


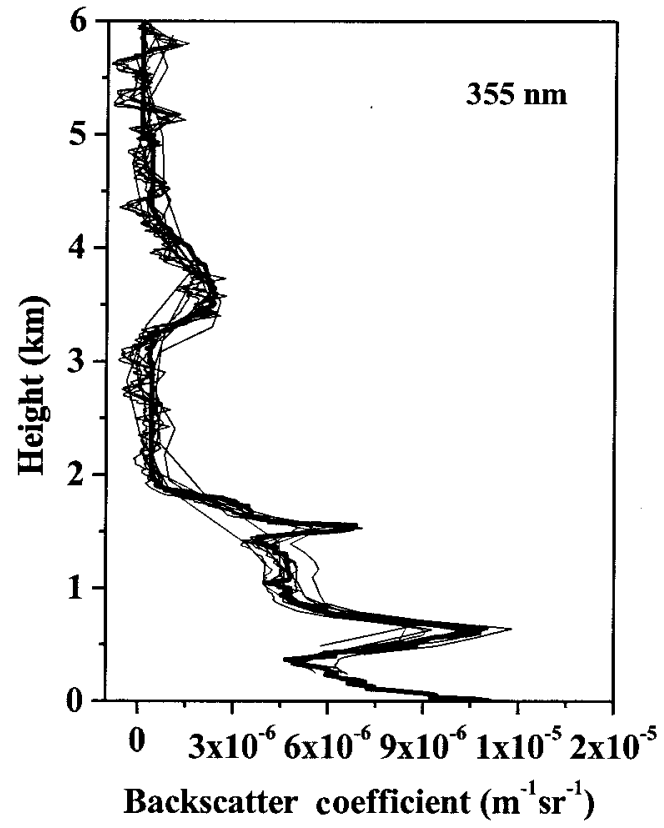

(a)

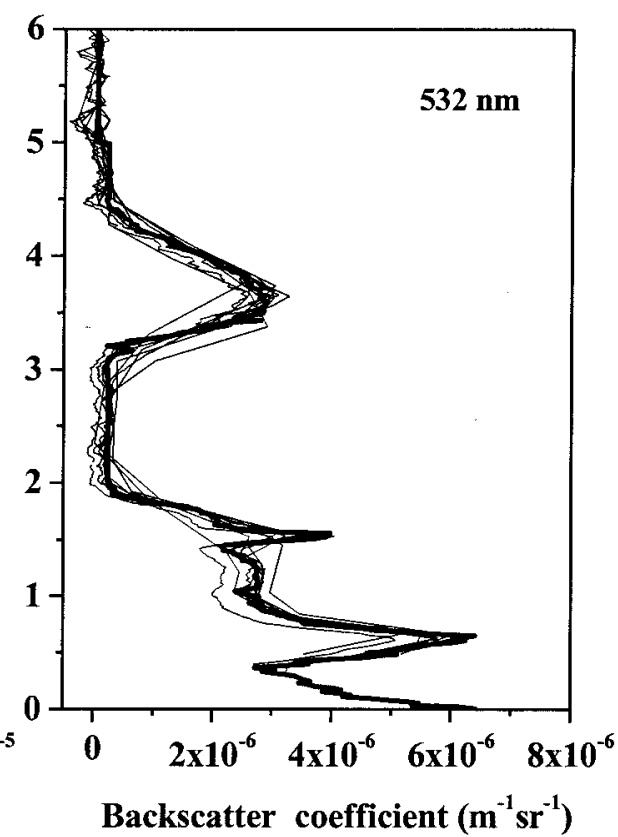

(b)

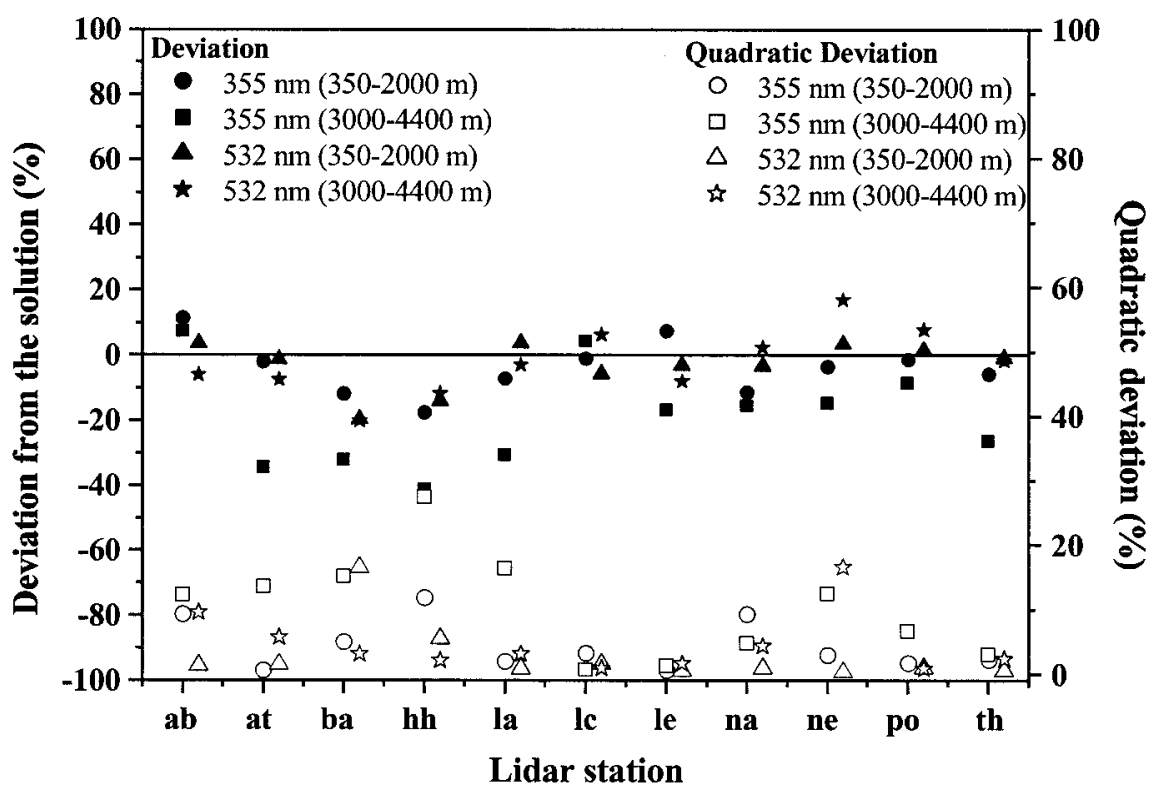

(c)

Fig. 5. (a), (b) Comparison of the backscatter coefficient profiles retrieved at $355 \mathrm{~nm}$ and $532 \mathrm{~nm}$ by each lidar station, and the corresponding solutions (thicker curves). (c) Mean deviations and mean quadratic deviations between the solution and the retrieved aerosol backscatter profiles at 355 and $532 \mathrm{~nm}$, calculated for two different height ranges (Stage I).

Figure 3(c) also shows that different algorithms and different altitude resolutions provide similar mean quadratic deviations for most of the groups for both wavelengths and height ranges. The absolute mean deviations between the extinction coefficients and the solution for both wavelengths and for each station are listed in Table 3 for Stage I. Results obtained for Stage I meet the requirements fixed within the EARLINET $^{4,5}$; the mean relative deviations are within $20 \%$ for most of the stations, and the absolute mean deviations are always less than $5 \times 10^{-5} \mathrm{~m}^{-1}$, also in the height range $2000-3000 \mathrm{~m}$, which is representative of a region with a low aerosol load.

Figure 4 shows the results for Stage II, where all the ancillary information has been provided to all groups and the effective spatial resolution has been fixed. Here the differences among the extinction profiles are within $10 \%$ and $20 \%$ in the $350-2000$ and in the 3000-4400-m height ranges, respectively, except at three stations (Athens, Barcelona, Thessaloniki) for which in some points they are as much as $40 \%$. With respect to Stage I, in this case, when the 
Table 5. Mean Absolute Deviations of the Aerosol Backscatter $\left(\times 10^{-6} \mathrm{~m}^{-1} \mathrm{sr}^{-1}\right)$ for Three Altitude Ranges (Stage I)

\begin{tabular}{|c|c|c|c|c|c|c|}
\hline \multirow{2}{*}{$\begin{array}{l}\text { Lidar } \\
\text { Group }\end{array}$} & \multicolumn{3}{|c|}{ At $355 \mathrm{~nm}$} & \multicolumn{3}{|c|}{ At $532 \mathrm{~nm}$} \\
\hline & $350-2000 \mathrm{~m}$ & $2000-3000 \mathrm{~m}$ & $3000-4400 \mathrm{~m}$ & $350-2000 \mathrm{~m}$ & $2000-3000 \mathrm{~m}$ & $3000-4400 \mathrm{~m}$ \\
\hline$a b$ & 0.79 & 0.37 & 0.21 & 0.09 & 0.09 & -0.20 \\
\hline at & -0.18 & -0.23 & -0.57 & -0.03 & -0.01 & -0.10 \\
\hline $\mathrm{ba}$ & -0.76 & -0.40 & -0.54 & -0.64 & -0.25 & -0.32 \\
\hline hh & -0.87 & -0.58 & -0.66 & -0.30 & -0.16 & -0.22 \\
\hline la & -0.36 & -0.22 & -0.36 & 0.15 & 0.06 & 0.11 \\
\hline lc & -0.003 & 0.20 & 0.13 & -0.15 & -0.02 & 0.14 \\
\hline le & 0.54 & -0.09 & -0.29 & -0.11 & -0.11 & -0.15 \\
\hline na & -0.79 & -0.12 & -0.30 & -0.09 & -0.02 & -0.01 \\
\hline ne & -0.26 & -0.002 & -0.16 & 0.23 & 0.15 & 0.33 \\
\hline po & -0.03 & -0.01 & -0.10 & 0.05 & 0.003 & 0.10 \\
\hline th & -0.29 & -0.37 & -0.44 & -0.003 & -0.02 & -0.11 \\
\hline
\end{tabular}

effective spatial resolution has been fixed, both mean and quadratic deviations are similar for the groups that use similar Raman algorithms such as a sliding linear least-squares fit, a second-order SavitzkyGolay digital filter, and a sliding average. In a quadratic fit, a polynomial fit, and a least-squares fit, the results in terms of mean deviations and quadratic deviations seem to be worse than for Stage I, and this could be related to the fact that for these kinds of data-processing procedures resolutions of $150 \mathrm{~m}$ up to $700 \mathrm{~m}, 300 \mathrm{~m}$ up to $1900 \mathrm{~m}$, and $735 \mathrm{~m}$ above $1900 \mathrm{~m}$, fixed for this intercomparison, were not the best choices because mean deviations and quadratic deviations depend strongly on the effective spatial resolution that is related to the number of points used in the fitting procedure. On average, statistical errors are within $20 \%$ in the first height range and within $30 \%$ in the second height range for both wavelengths; in this case errors are quite similar for each group because of the common fixed spatial resolution. The absolute mean deviations between the extinction coefficients and the solution for both wavelengths and for each station are listed in Table 4 for Stage II. Also for this stage, results meet the requirements fixed within the EARLINET. 4,5

This intercomparison showed the goodness of all the algorithms used. In particular, no large differences were noted in the aerosol extinction profiles obtained in the two stages of the intercomparison. In the 350-2000-m height range, some stations (Aberystwyth, Athens, Napoli, Neuchâtel, Thessaloniki) underestimated the solution [Fig. 3(c)]. The observed bias is a systematic effect caused by the unknown temperature and pressure profiles and wavelength parameter $k$ : An underestimation of 10 $\mathrm{K}$ in temperature leads to an overestimation of the Rayleigh correction with a consequent underestimation of the aerosol extinction of a few percent, and the choice of $k=1$ instead of $k=1.8$ introduces an underestimation of the aerosol extinction of approximately 3-4\%; in fact, this bias is no longer present in Stage II [Fig. 4(c)], where these parameters are known. In the 3000-4400-m height range, a negative bias is present for all groups for both stages because of the application of an average procedure that is necessary in all Raman algorithms for calculating the derivative of the logarithm of the ratio between the atmospheric number density and the range-corrected lidar-received power. Sharp gradients in the aerosol profile, as in our case above $3000-\mathrm{m}$, are systematically underestimated after vertical signal averaging. This demonstrates that the assumptions of atmospheric pressure and temperature profiles and of wavelength-dependence parameter $k$ generally introduce an uncertainty that is negligible compared with the uncertainty caused by the algorithm and the signal statistics, whereas systematic effects could be predominant in a height region where the lidar SNR is higher.

\section{B. Aerosol Backscatter}

Figure 5 illustrates the aerosol backscatter profiles obtained by each group compared with the solution for Stage I; spatial resolutions are the same as for the extinction calculation. This figure shows rather satisfactory agreement among all groups for both wavelengths, even though in this case no reference values for the backscatter have been provided. Mean statistical errors are $\sim 20 \%$ in the 350-2000-m height range and $\sim 30 \%$ in the second height range at both wavelengths. Figure 5(c) reports the relative mean deviations from the solution and the quadratic deviations for Stage I; mean deviations are typically within $20 \%$ in both height ranges for both 355- and $532-\mathrm{nm}$, with a few exceptions at $355 \mathrm{~nm}$ for the 3000-4400-m height range. The absolute mean deviations between the aerosol backscatter coefficients and the solution for both wavelengths and for each station are listed in Table 5 for Stage I.

Figure 6 shows the aerosol backscatter profiles obtained by each group for Stage II, for which the reference values for the backscatter were provided and a common altitude resolution was used. Results show satisfactory agreement in this stage, as well. Mean statistical errors are within $15 \%$ in the lower height range and $\sim 30 \%$ in the upper height range at $355 \mathrm{~nm}$; at $532 \mathrm{~nm}$ the errors are $\sim 10 \%$ in the lower height range and $\sim 20 \%$ in the upper height range. Figure 6 also illustrates mean deviations and quadratic deviations that show again, as has already 


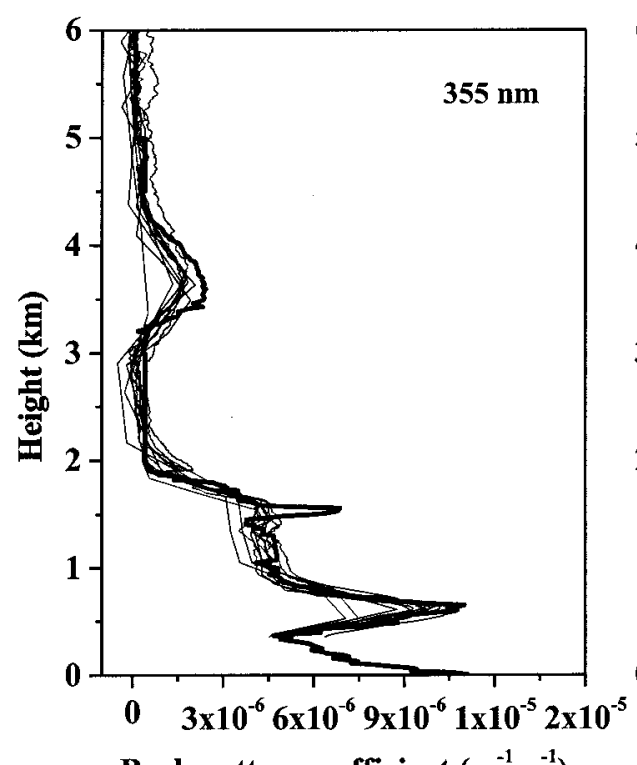

Backscatter coefficient $\left(\mathrm{m}^{-1} \mathrm{sr}^{-1}\right)$

(a)

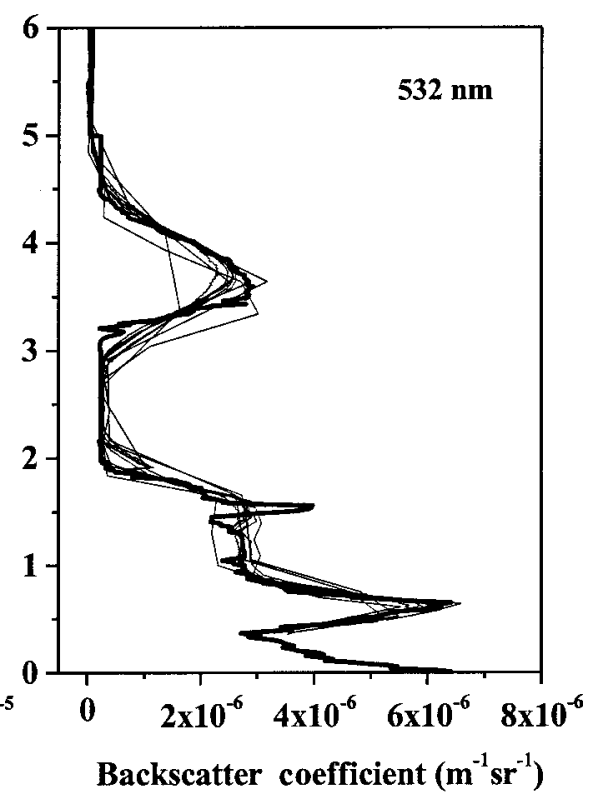

(b)

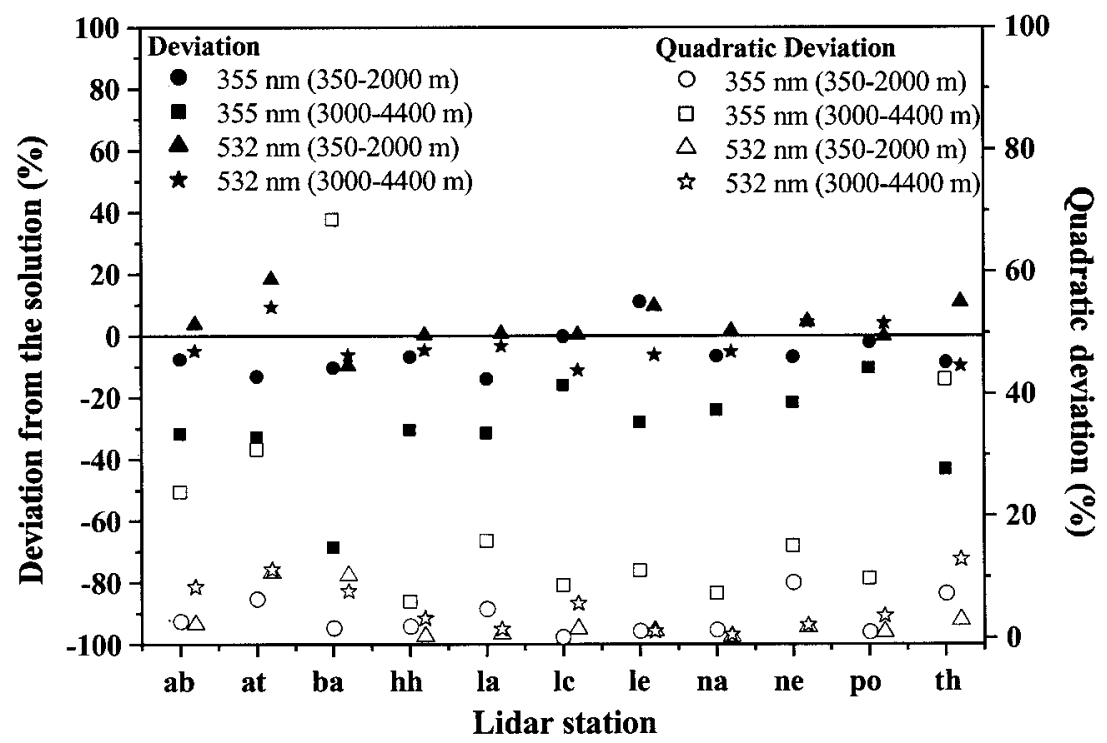

(c)

Fig. 6. (a), (b) Comparison of the backscatter coefficient profiles retrieved at 355 and $532 \mathrm{~nm}$ by each lidar station, and the corresponding solutions (thicker curves). (c) Mean deviations and mean quadratic deviations between the solution and the retrieved aerosol backscatter profiles at 355 and $532 \mathrm{~nm}$, calculated for two different height ranges (Stage II).

been seen for the aerosol extinction intercomparison, similar behavior for the Hamburg, L'Aquila, Lecce, Leipzig, Napoli, Neuchâtel, and Potenza lidar stations. These similar results are related to the similar data-handling procedures used at the same fixed altitude resolution. The absolute mean deviations are listed in Table 6.

This intercomparison of the algorithms for the backscatter profiles by use of Raman and elastic simulated lidar signals shows that, even without any reference for the backscatter, the retrievals starting from simultaneous Raman and elastic lidar signals are quite good, and this result demonstrates how much more powerful the combination of Raman and elastic lidar is than elastic lidar only. ${ }^{6}$

\section{Lidar Ratio}

Lidar ratio profiles were calculated for both stages by use of the corresponding aerosol extinction and backscatter profiles. Quantitative comparisons of the lidar ratio profiles with the solution were performed for both stages up to $2 \mathrm{~km}$, given that at high altitudes the low lidar SNR does not allow for the retrieval of lidar ratio profiles with reasonable statistical errors and fluctuations.

Figure 7(a) shows the aerosol backscatter coefficient 


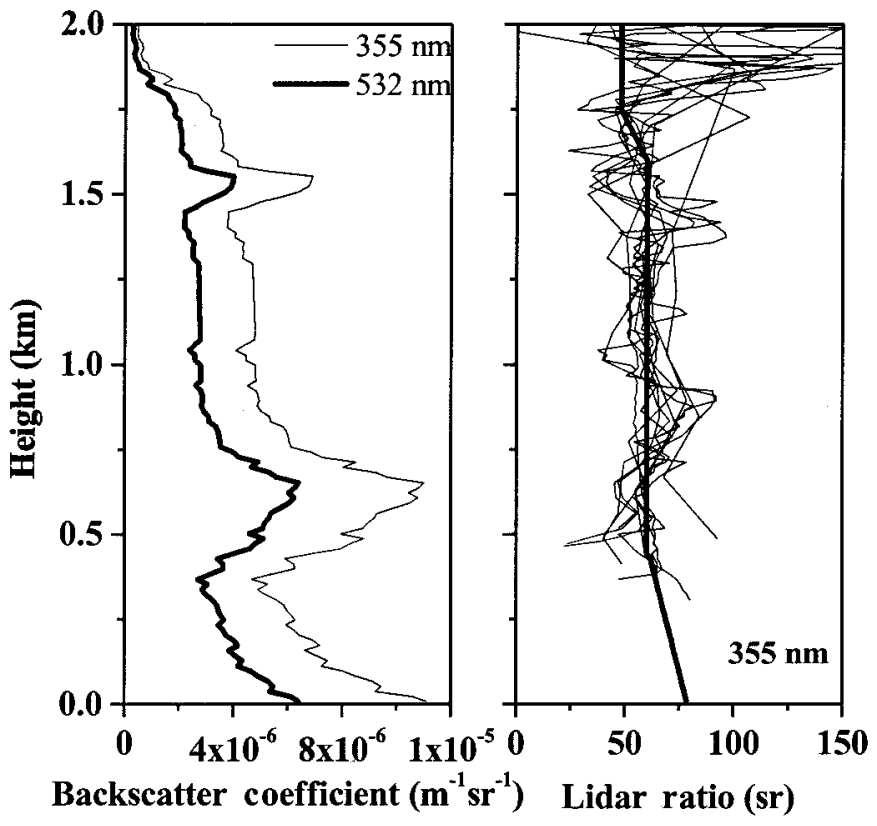

(a) (b)

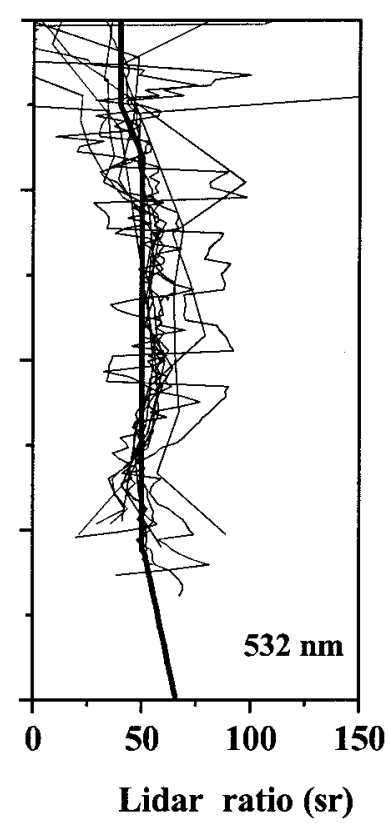

(c)

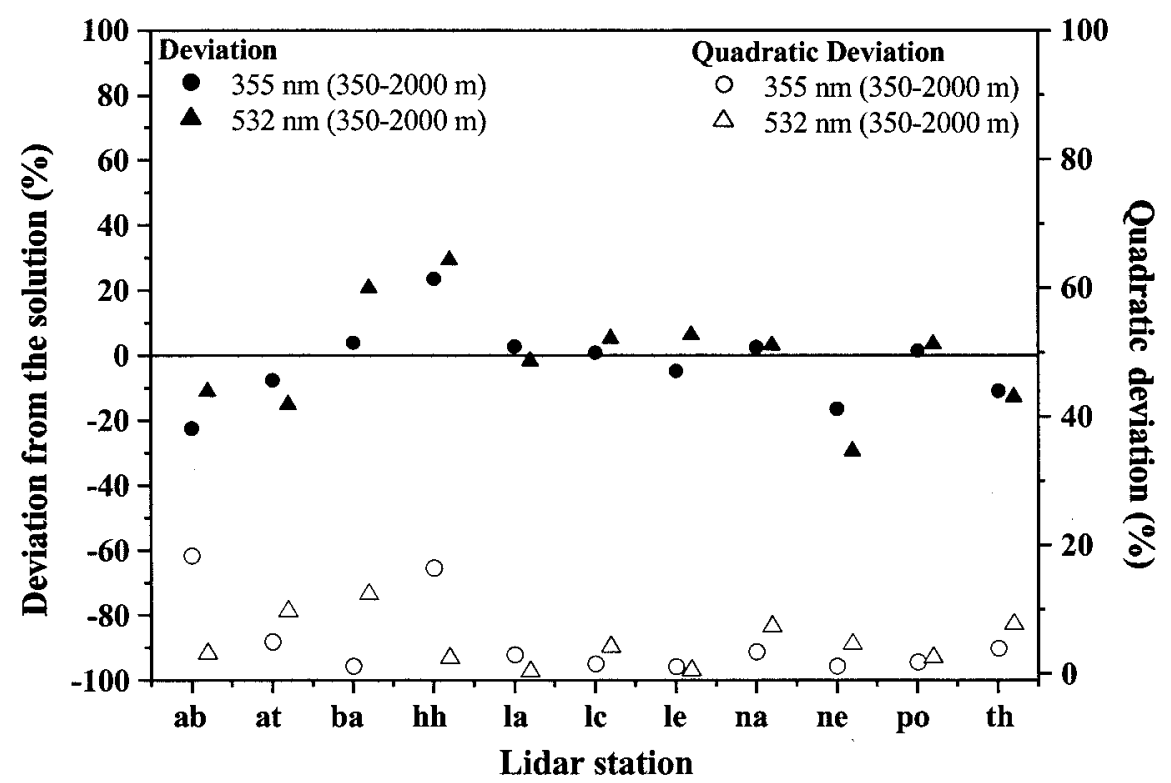

(d)

Fig. 7. (a) Aerosol backscatter coefficient profiles at 355 and $532 \mathrm{~nm}$ used as input in the simulation for the intercomparison. (b), (c) Comparison of the lidar ratio profiles retrieved at 355 and $532 \mathrm{~nm}$ by each lidar station, and the corresponding solutions (thicker curves). (d) Mean deviations and mean quadratic deviations between the solution and the retrieved lidar ratio profiles at 355 and $532 \mathrm{~nm}$ (Stage I).

profiles used as the input profile to produce the simulation. Figures 7(b) and 7(c) show a comparison between the lidar ratio profiles obtained by each station and the solution, at both 355 and $532 \mathrm{~nm}$, for Stage I. These results show satisfactory agreement with the solution within the aerosol layer up to $1.6 \mathrm{~km}$, whereas at higher altitudes, at the boundaries of the layer where the aerosol backscatter decreases, deviations from the solution become larger. For both wavelengths, mean deviations from the solution are always within $30 \%$, mean quadratic deviations are within $20 \%$, and statistical errors are within $30 \%$.

Figure 8 illustrates the comparison between the lidar ratio profiles for each station at both 355 and $532 \mathrm{~nm}$ for Stage II. Mean deviations from the solution are within $20 \%$ for each group and for both wavelengths; these values are consistent with the statistical errors that are always within $25 \%$ at both 355 and $532 \mathrm{~nm}$. Mean quadratic deviations for the lidar ratio are within $10 \%$ for most of the stations at 
Table 6. Mean Absolute Deviations of the Aerosol Backscatter $\left(\times 10^{-6} \mathrm{~m}^{-1} \mathrm{sr}^{-1}\right)$ for Three Altitude Ranges (Stage II)

\begin{tabular}{|c|c|c|c|c|c|c|}
\hline \multirow{2}{*}{$\begin{array}{l}\text { Lidar } \\
\text { Group }\end{array}$} & \multicolumn{3}{|c|}{ At $355 \mathrm{~nm}$} & \multicolumn{3}{|c|}{ At $532 \mathrm{~nm}$} \\
\hline & $350-2000 \mathrm{~m}$ & $2000-3000 \mathrm{~m}$ & $3000-4400 \mathrm{~m}$ & $350-2000 \mathrm{~m}$ & $2000-3000 \mathrm{~m}$ & $3000-4400 \mathrm{~m}$ \\
\hline$a b$ & -0.56 & -0.24 & -0.22 & 0.05 & 0.15 & -0.16 \\
\hline at & -0.63 & -0.72 & -0.62 & 0.68 & -0.004 & 0.03 \\
\hline ba & -0.10 & -0.69 & -0.91 & 0.22 & -0.05 & -0.07 \\
\hline $\mathrm{hh}$ & -0.24 & -0.10 & -0.38 & 0.11 & 0.11 & 0.07 \\
\hline la & -0.54 & -0.21 & -0.40 & 0.12 & 0.07 & 0.08 \\
\hline lc & 0.10 & 0.39 & -0.04 & 0.08 & 0.16 & 0.03 \\
\hline le & 0.59 & 0.17 & -0.30 & 0.36 & 0.19 & 0.09 \\
\hline na & -0.26 & -0.09 & -0.25 & 0.09 & 0.02 & 0.06 \\
\hline ne & -0.35 & -0.16 & -0.33 & 0.22 & 0.02 & 0.08 \\
\hline po & -0.16 & 0.09 & -0.18 & -0.01 & -0.02 & -0.03 \\
\hline th & -0.46 & -0.30 & -0.63 & 0.41 & 0.13 & 0.02 \\
\hline
\end{tabular}

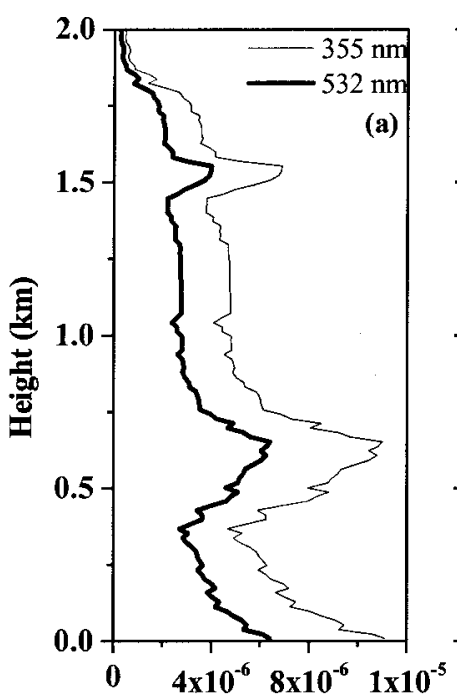

Backscatter coefficient $\left(\mathrm{m}^{-1} \mathbf{s r}^{-1}\right)$

(a)

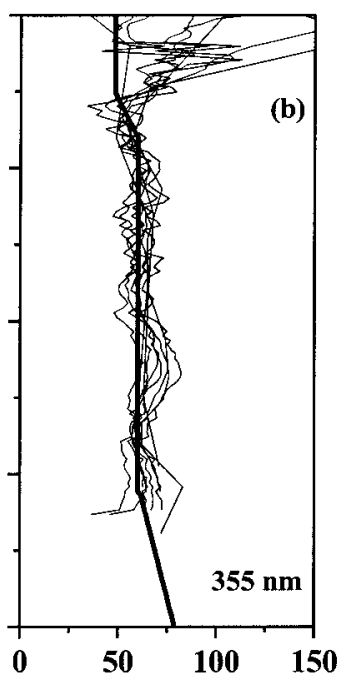

Lidar ratio (sr)

(b)

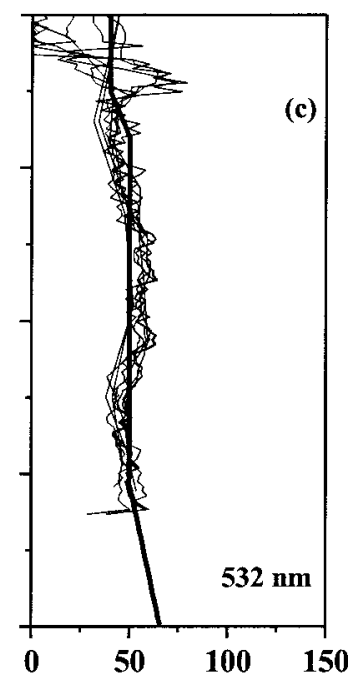

Lidar ratio (sr)

(c)

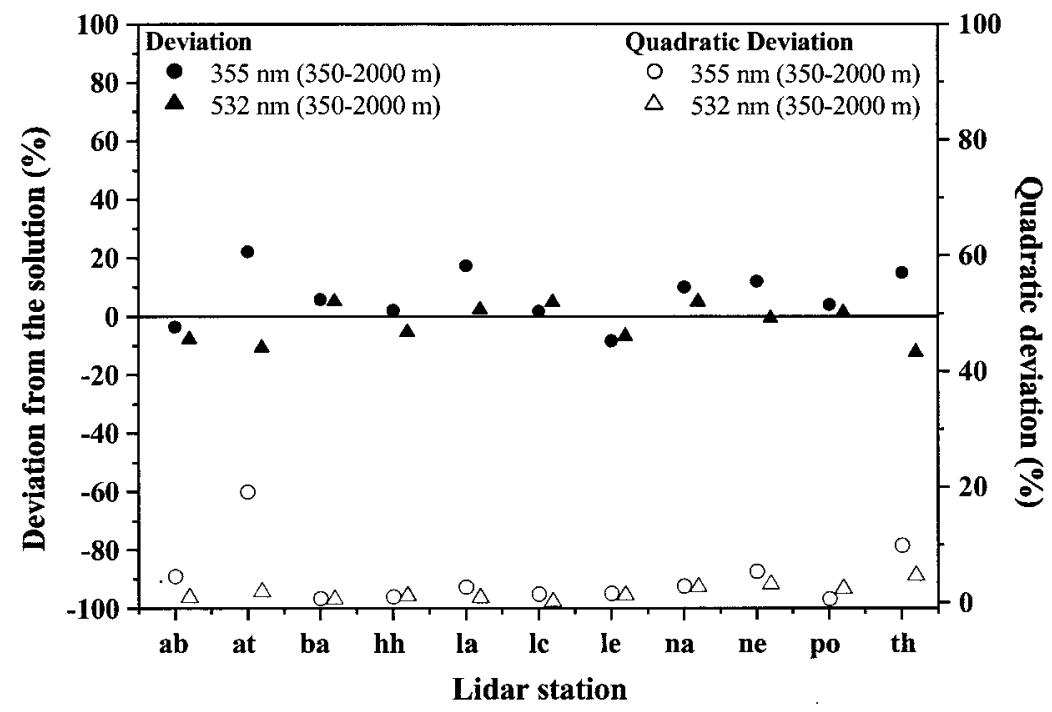

(d)

Fig. 8. (a) Aerosol backscatter coefficient profiles at 355 and $532 \mathrm{~nm}$ used as input in the simulation for the intercomparison. (b), (c) Comparison of the lidar ratio profiles retrieved at 355 and $532 \mathrm{~nm}$ by each lidar station, and the corresponding solutions (thicker curves). (d) Mean deviations and mean quadratic deviations between the solution and the retrieved lidar ratio profiles at 355 and $532 \mathrm{~nm}$ (Stage II). 
Table 7. Comparison of Mean Lidar Ratio Values Calculated in Height Region 3.6-3.9 km for Each Station with the Value Used in the Simulation

\begin{tabular}{lcc}
\hline & \multicolumn{2}{c}{ Mean Lidar Ratio (sr) } \\
\cline { 2 - 3 } Lidar & $\begin{array}{c}\text { At } 355 \mathrm{~nm} \\
(3.6-3.9 \mathrm{~km})\end{array}$ & $\begin{array}{c}\text { At } 532 \mathrm{~nm} \\
(3.6-3.9 \mathrm{~km})\end{array}$ \\
\hline Group & $69 \pm 12$ & $44 \pm 7$ \\
ab & $58 \pm 8$ & $47 \pm 5$ \\
ba & $57 \pm 14$ & $56 \pm 4$ \\
hh & $63 \pm 4$ & $49 \pm 1$ \\
la & $61 \pm 6$ & $49 \pm 2$ \\
lc & $61 \pm 5$ & $51 \pm 3$ \\
le & $59 \pm 6$ & $47 \pm 3$ \\
na & $56 \pm 4$ & $48 \pm 2$ \\
ne & $55 \pm 12$ & $48 \pm 8$ \\
po & $56 \pm 6$ & $48 \pm 2$ \\
th & $58 \pm 8$ & $51 \pm 5$ \\
solution & 60 & 50 \\
\hline
\end{tabular}

both wavelengths. As in Stage I, we can observe disagreement between the calculated lidar ratio profiles and the corresponding input profiles above $1600 \mathrm{~m}$, where the aerosol backscatter coefficient decreases. The results for Stage II shown in Fig. 8(c) are similar for all stations because of the fixed altitude resolution and also because in this stage more information has been provided.

The aerosol layer that is present from 3 to $4.4 \mathrm{~km}$ in the simulation (Fig. 2) is representative of an anomalous aerosol layer that could be related, for example, to forest-fire smoke plumes. It is reasonable in this case to compare the mean values of the lidar ratio in the layer that can be representative of the aerosol type. For this lofted layer the mean lidar ratio values given in Table 7 were calculated in the height region $3600-3900 \mathrm{~m}$ for each station to exclude the boundaries of the aerosol layer in the calculations. These values are in good agreement with the corresponding values of the solution at both 355 and $532 \mathrm{~nm}$; deviations from the solution are $2-15 \%$ at $355 \mathrm{~nm}$ and $2-12 \%$ at $532 \mathrm{~nm}$.

\section{Conclusions}

The results of an intercomparison of Raman lidar algorithms involving 11 lidar teams in the framework of the EARLINET network have been presented. The intercomparison has focused mainly on the aerosol extinction evaluation starting from nitrogen Raman lidar signals at two wavelengths and then on the retrieval of aerosol backscatter by use of the combined Raman elastic-backscatter lidar technique. This intercomparison shows that the aerosol extinction evaluation can be accomplished with good accuracy for all participating groups. For Stage I, mean deviations of the retrieved aerosol extinction profiles from the solution were within $15 \%$ and $20 \%$ in the $350-2000-$ and the 3000-4400-m height ranges, respectively, and, for Stage II were within $10 \%$ and $20 \%$ in the 350-2000- and the 3000-4400-m height ranges, respectively. The errors provided by each group are consistent with what was expected; moreover, all the calculated deviations from the solution were found to be within the expected errors. Results of the intercomparison for the aerosol extinction profiles show also that, with a common fixed spatial resolution, the various Raman algorithms used influenced not the errors but only the mean deviations from the solution.

This intercomparison has shown satisfactory results for the aerosol backscatter coefficient also. Both relative and absolute deviations typically were within the maximum allowed deviations that had been fixed within the EARLINET. This intercomparison shows in particular that, even without any reference value for the backscatter, the retrieval of the aerosol backscatter starting from simultaneous Raman and elastic lidar signals is satisfactory, demonstrating how much more powerful the Raman elastic-backscatter lidar technique is compared with that for which only elastic lidar signals are available.

Finally, the lidar ratio intercomparison has demonstrated the capability of each participating group to obtain lidar ratio profiles in the planetary boundary layer with a mean deviation from the solution within 30\% without any ancillary information (Stage I) and within $20 \%$ with additional information (Stage II). For the lidar ratio, a particular case was also considered: the evaluation of the mean value of this parameter within an aerosol layer at higher altitudes that is representative of typical layers related to special events such as Saharan dust outbreaks, forest fires, and volcanic eruptions. Good results were obtained for this case as well: Mean deviations from the solution were $2-15 \%$ at $355 \mathrm{~nm}$ and $2-12 \%$ at 532 nm.

We gratefully acknowledge the financial support provided for this study by the European Commission under grant EVR1-CT-1999-40003 and thank the Swiss Federal Office for Education and Sciences for support from the Observatoire Cantonal Neuchâtel (contract 99.0650-1).

\section{References}

1. F. A. Ackermann and H. Chung, "Radiative effects of airborne dust and regional energy budget at the top of the atmosphere," J. Appl. Meteorol. 31, 223-236 (1992).

2. J. T. Houghton, Y. Ding, D. J. Griggs, M. Noguer, P. J. van der Linden, and D. Xiaosu, Climate Change 2001: The Scientific Basis, contribution of Working Group I to the Third Assessment Report of the Intergovernmental Panel on Climate Change (Cambridge U. Press, Cambridge, 2001).

3. J. Bösenberg, A. Ansmann, J. M. Baldasano, D. Balis, C. Böckmann, B. Calpini, A. Chaikovsky, P. Flamant, A. Hågård, V Mitev, A. Papayannis, J. Pelon, D. Resendes, J. Schneider, N. Spinelli, T. Trickl, G. Vaughan, G. Visconti, and M. Wiegner, "EARLINET: a European aerosol research lidar network," in Advances in Laser Remote Sensing, A. Dabas, C. Loth, and J. Pelon, eds. (Editions de L'Ecole polytechnique, Palaiseau Cedex, France, 2001), pp. 155-158.

4. J. Bösenberg, V. Matthias, A. Amodeo, V. Amoridis, A. Ansmann, J. M. Baldasano, I. Balin, D. Balis, C. Böckmann, A. Boselli, G. Carlsson, A. Chaikovsky, G. Chourdakis, A. Com- 
eron, F. De Tomasi, R. Eixmann, V. Freudenthaler, H. Giehl, I. Grigorov, A. Hågård, M. Iarlori, A. Kirsche, G. Kolarov, L. Komguem, S. Kreipl, W. Kumpf, G. Larchevêque, H. Linné, R. Matthey, I. Mattis, A. Mekler, I. Mironova, V. Mitev, L. Mona, D. Müller, S. Music, S. Nickovic, M. Pandolfi, A. Papayannis, G. Pappalardo, J. Pelon, C. Pérez, R. M. Perrone, R. Persson, D. P. Resendes, V. Rizi, F. Rocadenbosch, J. A. Rodrigues, L. Sauvage, L. Schneidenbach, R. Schumacher, V. Shcherbakov, V. Simeonov, P. Sobolewski, N. Spinelli, I. Stachlewska, D. Stoyanov, T. Trickl, G. Tsaknakis, G. Vaughan, U. Wandinger, X. Wang, M. Wiegner, M. Zavrtanik, and C. Zerefos, "EARLINET: a European aerosol research lidar network to establish an aerosol climatology," Rep. 348 (Max-Planck-Institut für Meteorologie, Hamburg, Germany, 2003), http://lidarb.dkrz.de/ earlinet/.

5. V. Matthias, J. Bösenberg, V. Freudenthaler, A. Amodeo, D. Balis, A. Chaikovsky, G. Chourdakis, A. Comeron, A. Delaval, F. De Tomasi, R. Eixmann, A. Hågård, L. Komguem, S. Kreipl, R. Matthey, I. Mattis, V. Rizi, J. A. Rodriguez, V. Simeonov, and X. Wang, "Aerosol lidar intercomparison in the framework of the EARLINET project. 1. Instruments," Appl. Opt. 43, 961-976 (2004).

6. C. Böckmann, U. Wandinger, A. Ansmann, J. Bösenberg, V. Amiridis, A. Boselli, A. Delaval, F. De Tomasi, M. Frioud, A. Hågård, M. Horvat, M. Iarlori, L. Komguem, S. Kreipl, G. Larchevêque, V. Matthias, A. Papayannis, G. Pappalardo, F. Rocadembosch, J. A. Rodriguez, J. Schneider, V. Shcherbakov, and M. Wiegner, "Aerosol lidar intercomparison in the framework of the EARLINET project. 2. Aerosol backscatter algorithms," Appl. Opt. 43, 977-989 (2004).

7. A. Ansmann, M. Riebesell, and C. Weitkamp, "Measurement of atmospheric aerosol extinction profiles with a Raman lidar," Opt. Lett. 15, 746-748 (1990).

8. A. Ansmann, U. Wandinger, M. Riebesell, C. Weitkamp, and W. Michaelis, "Independent measurement of the extinction and backscatter profiles in cirrus clouds by using a combined Raman elastic-backscatter lidar," Appl. Opt. 31, 7113-7131 (1992).

9. R. T. H. Collis and P. B. Russell, "Lidar measurement of particles and gases by elastic backscattering and differential absorption," in Laser Monitoring of the Atmosphere, E. D. Hinkley, ed. (Springer-Verlag, Berlin, 1976), pp. 71-151.

10. S. T. Shipley, D. H. Tracy, E. W. Eloranta, J. T. Trauger, J. T. Sroga, F. L. Roesler, and J. A. Weinman, "A high spectral resolution lidar to measure optical scattering properties of atmospheric aerosols. I. Instrumentation and theory," Appl. Opt. 23, 3716-3724 (1983).

11. D. Gutkowicz-Krusin, "Multiangle lidar performance in the presence of horizontal inhomogeneities in atmospheric extinction and scattering," Appl. Opt. 32, 3266-3272 (1993).

12. M. Sicard, P. Chazette, J. Pelon, J. G. Won, and S.-C. Yoon, "Variational method for the retrieval of the optical thickness and backscatter coefficient from multiangle lidar profiles," Appl. Opt. 41, 493-502 (2002).

13. J. A. Reagan, D. M. Byrne, M. D. King, J. D. Spinhirne, and B. M. Herman, "Determination of the complex refractive index and size distribution of atmospheric particulates from bistatic-monostatic lidar and solar radiometer measurements," J. Geophys. Res. 85, 1591-1599 (1980).

14. D. D. Turner, R. A. Ferrare, L. A. H. Brasseur, and W. F. Feltz, "Automated retrievals of water vapor and aerosol profiles from an operational Raman lidar," J. Atmos. Ocean. Technol. 19, 37-50 (2002).

15. A. Amodeo, G. Pappalardo, U. Wandinger, V. Matthias, J. Bösenberg, M. Alpers, V. Amiridis, F. De Tomasi, M. Frioud, M. Iarlori, L. Komguem, G. Larchevêque, A. Papayannis, and $\mathrm{X}$. Wang, "Raman lidar algorithm intercomparison in the frame of EARLINET," in Proceedings of XXI International Laser Radar Conference-Part I (Defence R\&D CanadaValcartier, Val-Bélair, Canada, 2002), pp. 349-352.

16. R. M. Measures, Laser Remote Sensing: Fundamentals and Application (Wiley, New York, 1984).

17. J. A. Cooney, "Remote measurements of atmospheric water vapor profiles using the Raman component of laser backscatter," J. Appl. Meteorol. 9, 182-184 (1970).

18. S. H. Melfi, J. D. Lawrence, Jr., and M. P. McCormick, "Observation of Raman scattering by water vapor in the atmosphere," Appl. Phys. Lett. 15, 295-297 (1969).

19. D. A. Leonard and B. Caputo, "A single-ended atmospheric transmissometer," Opt. Eng. 13, 10-14 (1974).

20. G. Pappalardo, J. Bösenberg, D. Balis, A. Boselli, L. Komguem, G. Larchevêque, V. Matthias, L. Mona, I. Mattis, A. Papayannis, M. R. Perrone, and V. Rizi, "EARLINET measurements of the aerosol extinction-to-backscatter ratio," in Proceedings of XXI International Laser Radar Conference-Part I (Defence R\&D Canada-Valcartier, Val-Bélair, Canada, 2002), pp. 301-304.

21. J. A. Cooney, J. Orr, and C. Tomasetti, "Measurements separating the gaseous and aerosol components of laser atmospheric backscattering," Nature 224, 1098-1099 (1969).

22. S. H. Melfi, "Remote measurements of the atmosphere using Raman scattering," Appl. Opt. 11, 1605-1610 (1972).

23. D. N. Whiteman, S. H. Melfi, and R. A. Ferrare, "Raman lidar system for the measurement of water vapor and aerosol in the Earth's atmosphere," Appl. Opt. 31, 3068-3082 (1992).

24. J. F. Kaiser and W. A. Reed, "Data smoothing using low-pass digital filters," Rev. Sci. Instrum. 48, 1447-1457 (1977).

25. W. H. Press, B. P. Flannery, S. A. Teukolsky, and W. T. Vetterling, Numerical Recipes in FORTRAN: The Art of Scientific Computing, 2nd ed. (Cambridge, U. Press, Cambridge, 1992), pp. $127-128$ and $644-647$.

26. D. Whiteman, "Application of statistical methods to the determination of slope in lidar data," Appl. Opt. 38, 3360-3369 (1999).

27. D. N. Whiteman, "Examination of the traditional Raman lidar technique. I. Evaluating the temperature-dependent lidar equations," Appl. Opt. 42, 2571-2592 (2003).

28. D. N. Whiteman, W. F. Murphy, N. W. Walsh, and K. D. Evans, "Temperature sensitivity of an atmospheric Raman lidar system based on a XeF excimer laser," Opt. Lett. 18, 247-249 (1993).

29. R. A. Ferrare, S. H. Melfi, D. N. Whiteman, and K. D. Evans, "Raman lidar measurements of Pinatubo aerosols over southeastern Kansas during November-December 1991," Geophys. Res. Lett. 19, 1599-1602 (1992).

30. R. A. Ferrare, S. H. Melfi, D. N. Whiteman, M. Poellot, and Y. J. Kaufman, "Raman lidar measurements of aerosol extinction and backscattering. 2. Derivation of aerosol real refractive index, single scattering albedo, and humidification factor using Raman lidar and aircraft size distribution measurements," J. Geophys. Res. 103, 19673-19689 (1998).

31. R. A. Ferrare, D. D. Turner, L. A. Heilman, W. F. Feltz, O. Dubovik, and T. P. Tooman, "Raman lidar measurements of aerosol extinction-to-backscatter ratio over southern Great Plains," J. Geophys. Res. 106, 20333-20348 (2001).

32. U. Wandinger, "Multiple-scattering influence on extinction and backscatter coefficient measurements with Raman and high-spectral-resolution lidars," Appl. Opt. 37, 417-427 (1998).

33. J. Bösenberg, "Ground-based differential absorption lidar for water vapor and temperature profiling: methodology," Appl. Opt. 37, 3845-3860 (1998).

34. D. N. Stacey, "Rayleigh's legacy to modern physics: high resolution spectroscopy," Eur. J. Phys. 15, 236-242 (1994). 